Article

\title{
Anticancer Activities of Polyynes from the Root Bark of Oplopanax horridus and Their Acetylated Derivatives
}

\section{Lan-Zhen Meng ${ }^{1, \dagger}$, Wei-Hua Huang ${ }^{1, \dagger}$, Chong-Zhi Wang ${ }^{2}$, Chun-Su Yuan ${ }^{2, *}$ and Shao-Ping Li ${ }^{1, *}$}

1 State Key Laboratory of Quality Research in Chinese Medicine, Institute of Chinese Medical Sciences, University of Macau, Avenida da Universidade, Macau, China; E-Mail: Meng-1z@hotmail.com (L.-Z.M.); endeavor34852@aliyun.com (W.-H.H.)

2 Tang Center for Herbal Medicine Research, The Pritzker School of Medicine, University of Chicago, 5841 South Maryland Avenue, MC 4028, Chicago, IL 60637, USA;

E-Mail: CWang@dacc.uchicago.edu (C.-Z.W.)

$\dagger$ These authors contributed equally to this work.

* Authors to whom correspondence should be addressed; E-Mails: SPLi@umac.mo (S.-P.L.); CYuan@dacc.uchicago.edu (C.-S.Y.); Tel.: +853-8822-4692 (S.-P.L.); +1-773-702-1916 (C.-S.Y.); Fax: +853-2884 1358 (S.-P.L.); +1-773-834-0601 (C.-S.Y.).

Received: 12 April 2014; in revised form: 9 May 2014 / Accepted: 12 May 2014 /

Published: 14 May 2014

Abstract: Six polyynes OH-1 6, some of which are occur naturally in acetylated form, had been isolated and identified from the root bark of Oplopanax horridus (Devil's Club), a natural dietary supplement and medicinal plant in North America. During the evaluation of the polyynes' potential anticancer activities, sixteen more acetylated derivatives OHR-1 16 have synthesized and their anti-proliferation activity on MCF-7, MDA-MB-231, A549, HepG2 and LO2 cells assayed to elucidate their structure-activity relationships. The results showed that $\mathbf{O H}-1$ ( $(3 S, 8 S)$-falcarindiol) had the most potent anticancer activity, with IC $_{50}$ values of 15.3, 23.5, 7.7 and 4.7 $\mu \mathrm{M}$ on MCF-7, A549, HepG2 and MDA-MB-231 cells, respectively. For the primary structure-activity relationship, the anticancer activities of polyynes become weaker if their hydroxyl groups are acetylated, the terminal double bonds transformed into single bonds or they contain one more methylene group in the main skeleton chain. 
Keywords: polyynes; Oplopanax; anticancer; structure-activity relationship

\section{Introduction}

Polyynes, namely polyacetylenes, have been found in many food and dietary plants [1-5]. To date, pharmacological investigations have revealed that polyynes from natural sources show antibacterial, anti-fungal, antiinflammatory, nerotoxic and anticancer activities [6-9]. Polyynes were regarded to be responsible for many bioactivities of Oplopanax horridus, which has long history of medicinal use and as a dietary supplement. O. horridus was well-known and marketed in North America as Devil's Club extracts, which are also edible as a respiratory stimulant and expectorant, and used for rheumatoid arthritis, autoimmune conditions, eczema, type II diabetes, external and internal infections [10-15].

Recent studies have revealed that four purified polyynes from O. horridus showed potential anticancer activities [16-18]. All these polyynes possess hydroxy groups in their structures, and two of them, which occured naturally in acetylated form had weaker anti-proliferation effects. The primary hypothesis based on the anti-proliferation investigation of only these four polyynes on the selected cancer cell lines was that acetylation of polyynes had a negative contribution to their anticancer activities. However, as the two acetylated polyynes had 18 carbon atoms in the main skeleton chain $(\mathrm{C} 18$ polyynes) while the others had 17 carbon atoms as the main structural chain (C17-polyynes). It seems that they could not be compared diretly together to reach that conclusion [17].

During the course of discovering interesting anticancer molecules from the title plant, six polyynes OH-1 OH-6 (Figure 1) had been purified from hydrophobic parts of the herbal medicine extracts and identified. Some of these compounds had displayed anti-proliferation activity against certain cancer cell lines [17,19]. Among the polyynes, $(3 S, 8 S)$-falcarindiol had been obtained separately from $(3 R, 8 S)$-falcarindiol, which was also reported to have anticancer activities [20]. Since two of the polyynes from $O$. horridus naturally occur acetylated, sixteen more acetylated derivatives OHR-1 OHR-16 (Figure 1) have now been synthesized for the evalutation of the polyynes' potential anticancer activities. The possible mechanisms and structure-function relationships in anti-proliferative activity were also studied.

\section{Results and Discussion}

\subsection{Chemistry}

The known compounds were identified by comparing their physical and spectroscopic data with values reported in the literature. The structures of acetylated compounds were characterized by IR, ${ }^{1} \mathrm{H}-\mathrm{NMR},{ }^{13} \mathrm{C}-\mathrm{NMR}$, and HMBC spectra. Especially, the position of the acetyl group in the compounds was elucidated and fixed by the HMBC spectra. The purity $(\geq 96 \%)$ of the target compounds was verified by HPLC.

Six polyynes OH-1 OH-6 had been isolated and purified from the root bark of O. horridus. Acetylated polyynes OHR-1 OHR-16 were synthesized from OH-1 OH-6 with acetic anhydride in ethyl acetate with sodium carbonate added to the stirring mixtures. After quenching the reactions, the 
reaction mixture was cooled to room temperature and evaporated to remove the organic solvents. The residue was diluted with water and then extracted with chloroform. The chloroform layer was evaporated to remove the organic solvents. After that, the acetylated products were subjected to chromatographic separation to obtain the derivatives OHR-1 OHR-16.

Figure 1. The structures of the isolated and derivative polyynes.
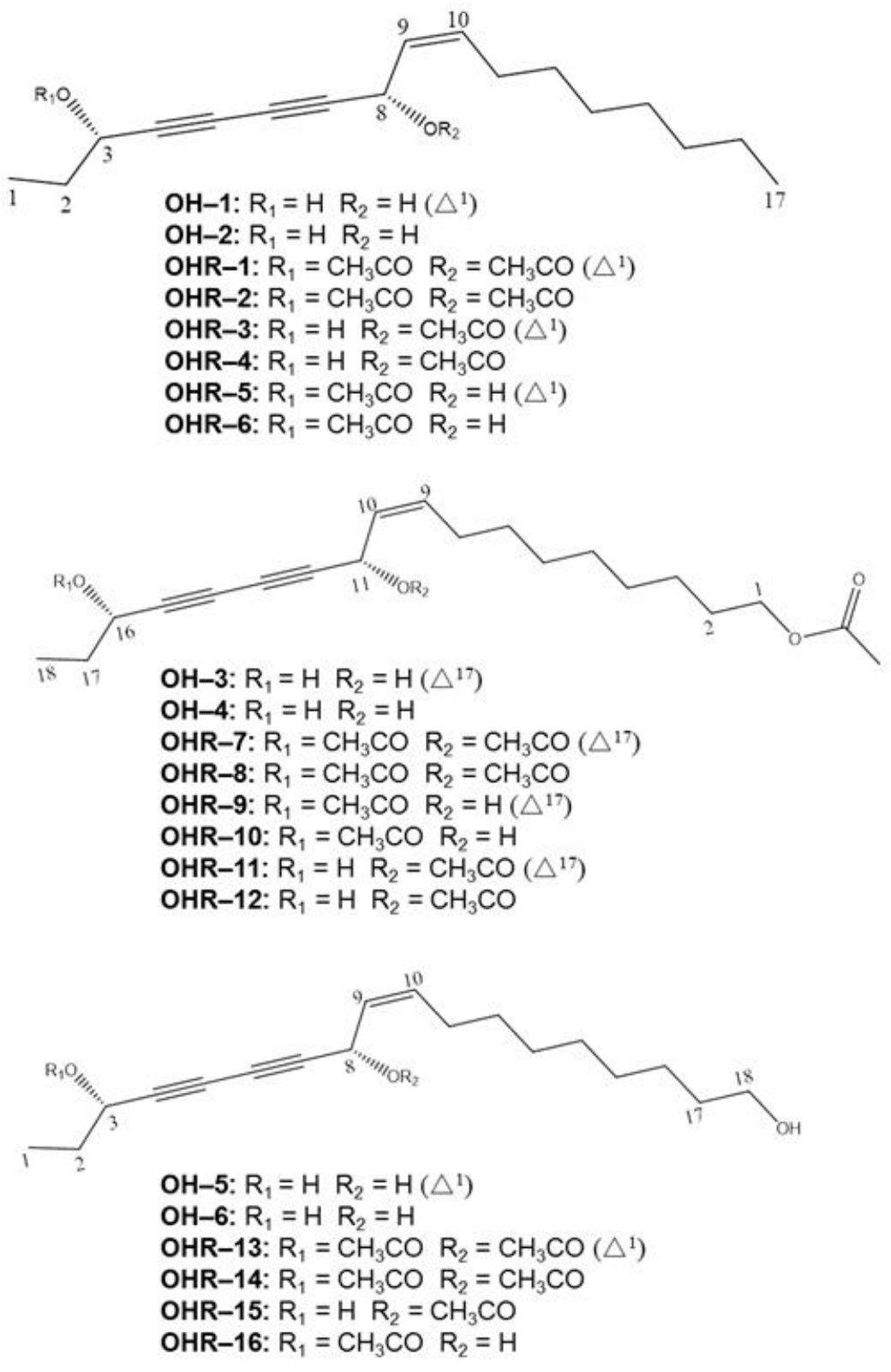

\subsection{Effects of the 22 Polyynes on Proliferation of Selected Cancer Cells}

The polyynes isolated from $O$. horridus have been evaluated for antiproliferative effects on some selected cancer cell lines such as human breast cancer cell line MCF-7, non-small cell lung cancer (NSCLC) cells, human colorectal cancer cell lines HCT-116 and SW-480 [21-23]. As shown in Table 1, the 22 polyynes exhibited different antiproliferative effects on the human breast cancer MCF-7, human lung adenocarcinoma epithelial A549, liver hepatocellular HepG2 and human breast cancer $\mu \mathrm{M}-231$ cell lines. At the adopted concentrations (1-300 $\mu \mathrm{M})$, polyynes OHR-7 8 and OHR-13 16 were not 
observed to inhibit the cancer cell growth of any of the four cell lines. OHR-13 and OHR-14 showed some antiproliferative effects on MDA-MB-231 cancer cells at about $150 \mu \mathrm{M}$, but such effects were not observed in other cancer cell lines. Moreover, other polyynes showed potentially different cell growth inhibition of the four cancer cell lines.

Table 1. Anticancer activities of polyynes from $O$. horridus and their acetylated derivatives.

\begin{tabular}{|c|c|c|c|c|c|}
\hline \multirow{2}{*}{ Polyynes } & \multicolumn{5}{|c|}{$\mathrm{IC}_{50}(\mu \mathrm{M})$} \\
\hline & A549 & MCF-7 & HepG2 & LO2 & MDA-MB-231 \\
\hline OH-1 & $23.5 \pm 4.1$ & $15.3 \pm 0.3$ & $7.7 \pm 1.3$ & $8.7 \pm 0.5$ & $4.7 \pm 1.4$ \\
\hline ОН-2 & $44.1 \pm 9.4$ & $27.5 \pm 2.2$ & $38.4 \pm 7.5$ & $30.2 \pm 4.8$ & $14.7 \pm 2.7$ \\
\hline OH-3 & $98.0 \pm 6.3$ & $93.6 \pm 6.1$ & $47.2 \pm 5.9$ & $90.3 \pm 6.4$ & $16.5 \pm 2.2$ \\
\hline OH-4 & $109.9 \pm 0.8$ & $100.0 \pm 7.0$ & $69.1 \pm 1.8$ & $91.9 \pm 13.4$ & $87.8 \pm 7.9$ \\
\hline OH-5 & $150-300$ & $94.4 \pm 7.3$ & $48.3 \pm 5.9$ & $91.0 \pm 9.5$ & $49.0 \pm 10.9$ \\
\hline OH-6 & $85.7 \pm 13.2$ & $106 \pm 13.2$ & $45.3 \pm 6.3$ & $90.8 \pm 4.0$ & $55.7 \pm 11.8$ \\
\hline OHR-1 & $>300$ & $>300$ & $114.9 \pm 17.1$ & $>300$ & $13.9 \pm 3.4$ \\
\hline OHR-2 & $24.7 \pm 5.6$ & $36.9 \pm 4.8$ & $6.6 \pm 1.5$ & $32.1 \pm 9.0$ & $4.8 \pm 0.5$ \\
\hline OHR-3 & $31.4 \pm 4.3$ & $25.8 \pm 5.8$ & $31.5 \pm 2.1$ & $31.5 \pm 4.0$ & $6.6 \pm 0.8$ \\
\hline OHR-4 & $33.3 \pm 8.5$ & $28.0 \pm 2.9$ & $59.5 \pm 3.1$ & $34.3 \pm 1.5$ & $23.4 \pm 3.2$ \\
\hline OHR-5 & $30.1 \pm 4.4$ & $30.6 \pm 3.1$ & $43.7 \pm 6.6$ & $31.1 \pm 1.8$ & $13.9 \pm 5.8$ \\
\hline OHR-6 & $97.5 \pm 8.2$ & $59.6 \pm 7.5$ & $38.5 \pm 6.2$ & $46.1 \pm 11.7$ & $36.2 \pm 13.4$ \\
\hline OHR-7 & $>300$ & $>300$ & $>300$ & $>300$ & $>300$ \\
\hline OHR-8 & $>300$ & $>300$ & $100-300$ & $>300$ & $19.6 \pm 6.9$ \\
\hline OHR-9 & $83.1 \pm 8.4$ & $81.3 \pm 1.0$ & $59.9 \pm 3.0$ & $86.2 \pm 11.3$ & $52.0 \pm 7.5$ \\
\hline OHR-10 & $100.9 \pm 7.3$ & $94.3 \pm 6.1$ & $78.4 \pm 6.5$ & $100-300$ & $56.7 \pm 6.9$ \\
\hline OHR-11 & $98.2 \pm 17.5$ & $78.1 \pm 3.4$ & $77.0 \pm 9.5$ & $93.1 \pm 14.0$ & $51.5 \pm 8.4$ \\
\hline OHR-12 & $100-300$ & $90.7 \pm 0.3$ & $100-300$ & $100-300$ & $77.7 \pm 1.9$ \\
\hline OHR-13 & $>300$ & $>300$ & $>300$ & $>300$ & $137.0 \pm 28.4$ \\
\hline OHR-14 & $>300$ & $>300$ & $150-300$ & $>300$ & $155.5 \pm 35.5$ \\
\hline OHR-15 & $>300$ & $>300$ & $>300$ & $>300$ & $100-300$ \\
\hline OHR-16 & $>300$ & $>300$ & $>300$ & $>300$ & $>300$ \\
\hline
\end{tabular}

In A549 cells, OH-3 6 and OHR-2, 5, 9 11 showed moderate antiproliferative effects, with IC50S of more than $80 \mu \mathrm{M}$. Cell growth of A549 could be inhibited by $50 \%$ by $\mathbf{O H - 1} \sim \mathbf{2}$ and $\mathbf{O H R - 3} \mathbf{4}, \mathbf{6}$ at the concentrations of $23.5 \pm 4.1 \mu \mathrm{M}, 44.1 \pm 9.4 \mu \mathrm{M}, 30.1 \pm 4.4 \mu \mathrm{M} 31.4 \pm 4.3 \mu \mathrm{M}$ and $33.3 \pm 8.5 \mu \mathrm{M}$, respectively (Table 1). OH-1 and OHR-3 showed stronger effects in that A549 cell growth was inhibited by $95.6 \%$ and $90.8 \%$, respectively, when administrated at $60 \mu \mathrm{M}$ (both $p<0.01$ ). In A549 cells, OH-1 and OHR-3 showed the most potent antiproliferative effects.

Similar results were also observed in MCF-7 cells. OH-3 6 and OHR-5, 9 11 also exhibited moderate antiproliferative effects as in A549 cells. The $\mathrm{IC}_{50}$ values of $\mathbf{O H - 1} \mathbf{2}$ and $\mathbf{O H R - 3 \sim 4 ,} 6$ were observed at the concentration of $15.3 \pm 0.3 \mu \mathrm{M}, 27.5 \pm 2.2 \mu \mathrm{M}, 30.6 \pm 3.1 \mu \mathrm{M}, 25.8 \pm 5.8 \mu \mathrm{M}$ and $28.0 \pm 2.9 \mu \mathrm{M}$, respectively, which were lower on this cell line than those of A549 cells (Table 1). Antiproliferative effects of other polyynes on MCF-7 cells were almost the same with that on A549 cells. Moreover, $\mathbf{O H}-1$ showed the most potent antiproliferative effects in this cell line. 
In HepG2 and MM-231 cells, OH-4 and OHR-9 11 displayed moderate antiproliferative effects on the two cancer cell lines at lower concentrations than those of A549 and MCF-7 cell lines (Table 1). The IC50 values of OH-1 3, 5 6 and OHR-3 6 were observed much lower on this cell lines than those of A549 and MCF-7 cells (Table 1). Among all the polyynes, OH-1 also showed the most potent antiproliferative effects in these two cell lines, with $\mathrm{IC}_{50}$ values of $7.7 \pm 1.3 \mu \mathrm{M}$ and $4.7 \pm 1.4 \mu \mathrm{M}$, respectively.

\subsection{Anti-Proliferative Activity and Possible Structure-Activity Relationships}

Anti-proliferative tests of the six isolated polyynes OH-1 OH-6 and their derivatives OHR-1 OHR-16 were conducted on four cancer cell lines and a normal human hepatic cell line. As shown in Table 1, the 22 compounds exhibited different extents of anti-proliferative activity on the cancer cell lines with various $\mathrm{IC}_{50}$ values.

The biological activities of the polyynes with same structure features were compared (Figure 2). In Figure 2A, the anti-proliferation effects of all the isolated compounds $\mathbf{O H - 1} \sim \mathbf{O H}-6$ showed that $\mathbf{O H}-1$, OH-3 and OH-5 had stronger activities than OH-2, OH-4 and OH-6 on all the investigated cancer cell lines, except for OH-5 and OH-6 on A549 cells, respectively. The OH-5 and OH-6 effects on A549 cells deviated, possibly due to different mechanisms on anticancer activity of this cell line. Additionally, OH-1 and OH-2 containing 17 carbon atoms in the main chain (C17-polyynes) displayed higher activity than other polyynes consisting of 18 carbon atoms as the structure skeleton chain (C18-polyynes).

In Figure 2B, the acetylated polyynes OHR-3, OHR-9 and OHR-12 show higher activities than OHR-5, OHR-10 and OHR-16 on all the cancer cell lines. These polyynes had their acetyl groups connected with the hydroxyls in the middle of the carbon chain. Among them, OHR-3 and OHR-5 derivatizated from $\mathbf{O H}-1$ and $\mathbf{O H}-2$, respectively, possessed higher inhibition than other acetylated $\mathrm{C} 18$ polyynes. In Figure 2C, the acetylated polyynes OHR-4 and OHR-11 possessed better activities than OHR-6 and OHR-11 toward all the cancer cell lines except A549 cells, respectively. OHR-13, OHR14 and OHR-15 even exhibited no cytotoxicity on any of the selected cancer cell lines except weak activity on MDA-MB-231 cells $\left(\mathrm{IC}_{50}>120 \mu \mathrm{M}\right)$. These polyynes synthesized with the acetyl group connected with the hydroxyl near the end of the carbon chain were compared with the ones in Figure $2 \mathrm{~B}$ to possibly conclude that the hydroxyl at the end of the carbon chain contributed more to the anticancer activity than the hydroxyl in the middle of the carbon chain. In Figure 2D, OHR-1, OHR-2, OHR-7 and OHR-8 almost showed no cytotoxicity toward most of the cancer cell lines when all the hydroxyls in these polyynes were substituted, although OHR-1 and OHR-8 had weak effects on MCF-7 and HepG2 cells with $\mathrm{IC}_{50}>150 \mu \mathrm{M}$.

For these similar polyynes, the anti-proliferation effects data showed that the compounds with terminal ethylenic bonds exhibited higher activity compared to the polyynes with terminal single bond, without consideration of the ones ( $\mathrm{IC}_{50} \geq 300 \mu \mathrm{M}$ ); The $\mathrm{C}-17$ polyynes possesed stronger activities than the C18-polyynes, which has one more methylene group than the C17-polyynes except the polyynes with $\mathrm{IC}_{50}$ values more than $300 \mu \mathrm{M}$. In addition, hydroxypolyynes had higher activity than acylated polyynes. The primary structure-activity analysis thus showed that the observed inhibitions were influenced mostly by the carbon chain length, terminal ethenyl, hydroxyl groups and acylations of polyynes.

Moreover, the compounds' effects on the human normal hepatic cells was investigated to evaluate their potential hepatotoxicity in vitro. It was found that the compounds with higher anti-proliferative activity presented more potential cytotoxic effect on normal human hepatic cells as well (Table 1), which 
means these compounds may have potential hepatotoxicity in vivo. Actually, the safety and efficiency of $O$. horridus have not been evaluated totally thus far though it has a long history of use medicinally and as a dietary supplement $[21,24]$, so more studies are definitely needed.

Figure 2. The anti-proliferative effects of the similar polyynes on MCF-7 cells, A549 cells, HepG2 cells and MDA-MB-231 cells. (A) all the natural polyynes; (B) the polyynes with the hydroxyl in the middle of the carbon chain displaced; $(\mathbf{C})$ the polyynes with the hydroxyl near the end of the carbon chain; (D) the polyynes with no hydroxyls.
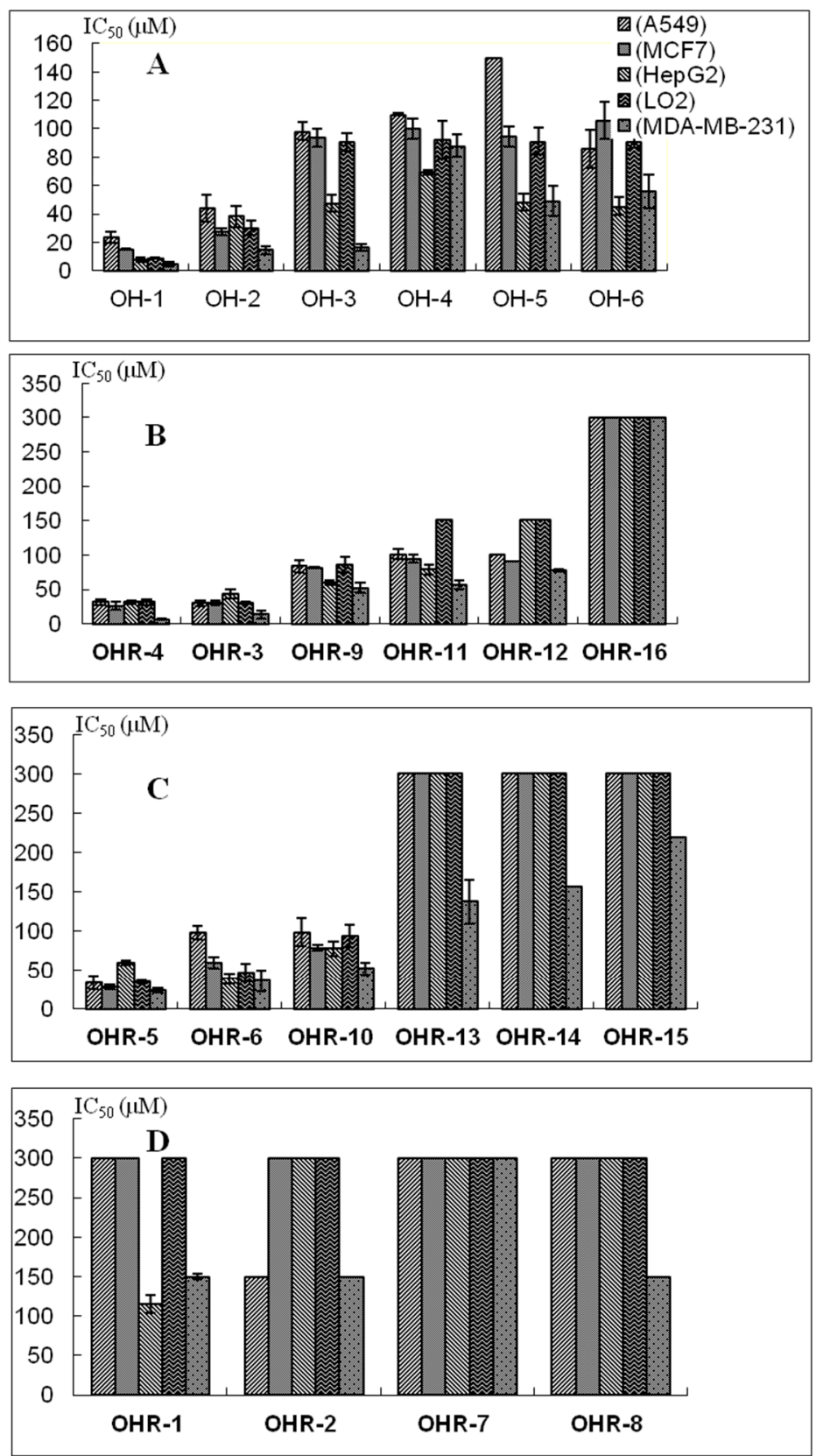

\subsection{Apoptosis and Cell Cycle Assays}

Next, cell cycle analysis and apoptosis assays were performed on the cancer cells. Previous work had reported that $\mathbf{O H - 1} \sim \mathbf{4}$ exhibited potential anticancer acitives on human breast cancer and colon cancers 
through cell arrest in $\mathrm{G} 2 / \mathrm{M}$ phase and induction of appoptosis at both earlier and later stages [17]. In this study, the potential mechanisms of the four new compounds OHR-1, -2, $\mathbf{- 3}$ and $\mathbf{- 5}$ with the strongest anti-proliferative activity among the series of acylated polyynes were investigated. It was found that these four acylated polyynes could induce obvious apoptosis in MM-231 cells, which showed classical apoptotic morphology, chromatin condensation and apoptotic bodies (Figure 3) with Hoechst staining.

Figure 3. Detection of apoptosis in MDA-MB-231 cells by Hochest-staining. Treated cells were stained with Hoechst 33342, and then observed under a fluorescent microscope (magnification of $\times 400$ ). (A) Sovent control treated MDA-MB-231 cells; (B-E) OHR-1 $(15 \mu \mathrm{M})$, OHR-2 $(5 \mu \mathrm{M})$, OHR-3 $(10 \mu \mathrm{M})$ and OHR-5 $(15 \mu \mathrm{M})$ treated MDA-MB-231 cells for $12 \mathrm{~h}$. The yellow arrows indicated classic apoptosis characteristics in cells with morphology change, chromatin condensation and apoptotic bodies.
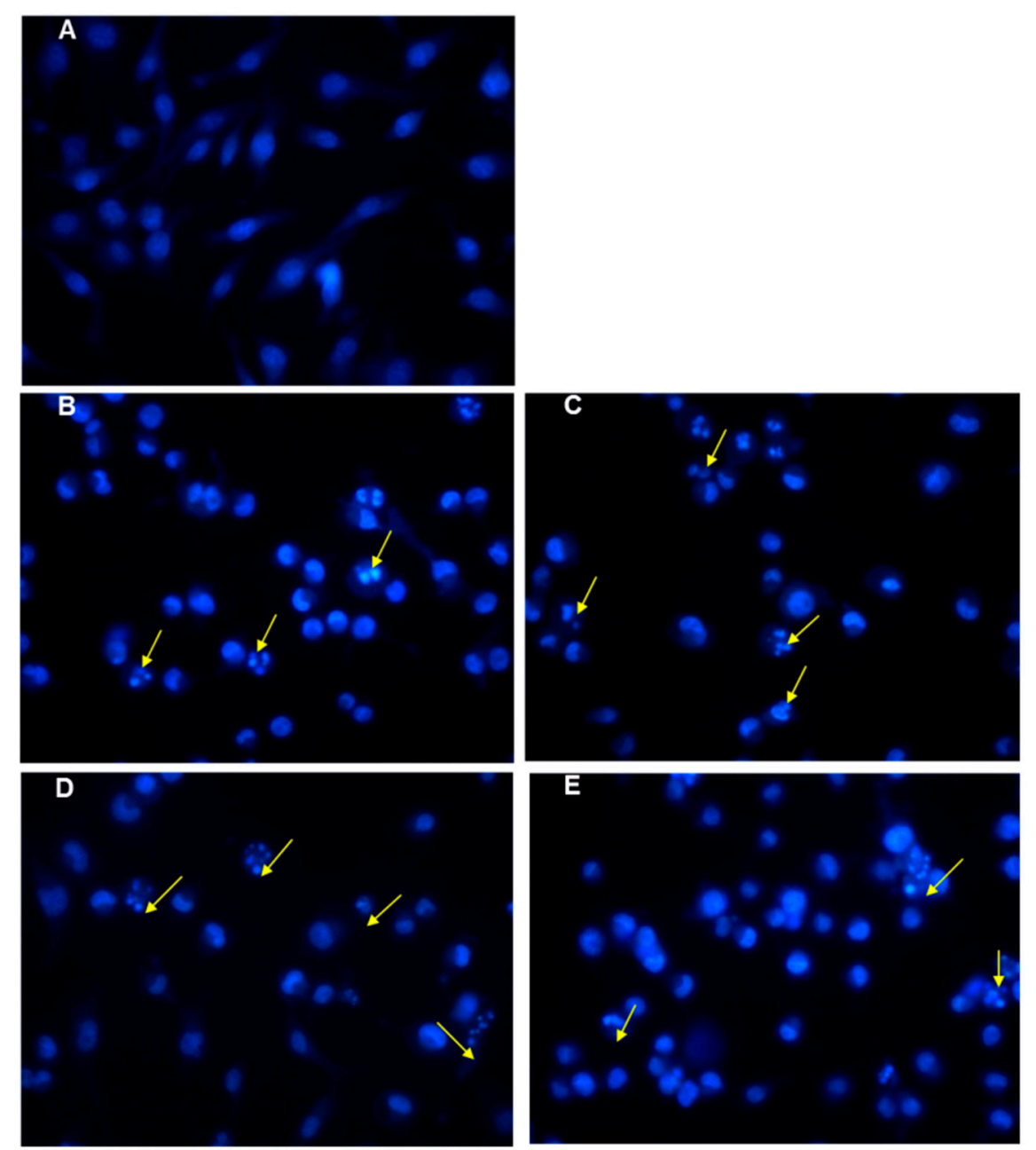

On the other hand, JC-1 dye was applied to test the $\Delta \psi \mathrm{m}$, which is an important parameter of mitochondrial function used as an indicator of cell health. In apoptotic cells with low $\Delta \psi \mathrm{m}, \mathrm{JC}-1$ remained in the monomeric form, and showed only green fluorescence in cells. The results showed that OHR-1, -2, -3 and -5 at high concentration could induce MM-231 cells apoptosis by decreasing the $\Delta \psi \mathrm{m}$, indicated by a change color from red to green fluorescence (Figures $4 \mathrm{~A}-\mathrm{E}$ ) and increasing green to red fluorescence intensity ratio (Figure 4F). Moreover, their influences on the MM-231 cell cycle 
were determined by PI staining and flow cytometry analysis. It was observed that OHR-1, -2, -3 and -5 could arrest MM-231 cells in $\mathrm{G} 2 / \mathrm{M}$ phases by $14.4 \% \pm 3.9 \%$ compared to the solvent control. The arrest rates at low conentration were $24.6 \% \pm 3.6 \%, 22.6 \% \pm 2.6 \%, 24.2 \% \pm 2.9 \%$ and $33.2 \% \pm 4.6 \%$, repectively, while at high concentration they were $31.7 \% \pm 3.2 \%, 30.4 \% \pm 3.1 \%, 25.6 \% \pm 7.5 \%$ and $38.0 \% \pm 1.7 \%$, repectively, as shown in Figure 5.

Figure 4. Effect of OHR-1, -2, -3 and -5 on mitochondrial potential in MDA-MD-231 cells. Treated cells stained by JC-1 dye and observed by fluorescence microscopy (magnification of $\times 400)$. (A1, A2) Solvent control-treated cells showed most of cells had stronger Jaggregation stained red fluorescence. (B1-E1, B2-E2) OHR-1 $(15 \mu \mathrm{M})$, OHR-2 $(5 \mu \mathrm{M})$, OHR-3 $(10 \mu \mathrm{M})$ and OHR-5 $(15 \mu \mathrm{M})$ treated MDA-MB-231 cells show a majority of cells stained green fluorescence due to low $\triangle \Psi \mathrm{m}$. (F) Analysis of the $\Delta \Psi \mathrm{m}$ (ration of green $/ \mathrm{red}$ fluorescence intensity) in cells measured by flow cytometry. The data were expressed as ratio of $\Delta \psi \mathrm{m}$ between OHR-1, -2, $\mathbf{- 3}$ and $\mathbf{- 5}$ treatments and control cells (solvent vehicle set at $100 \%) . * p<0.05$ vs. vehicle control.
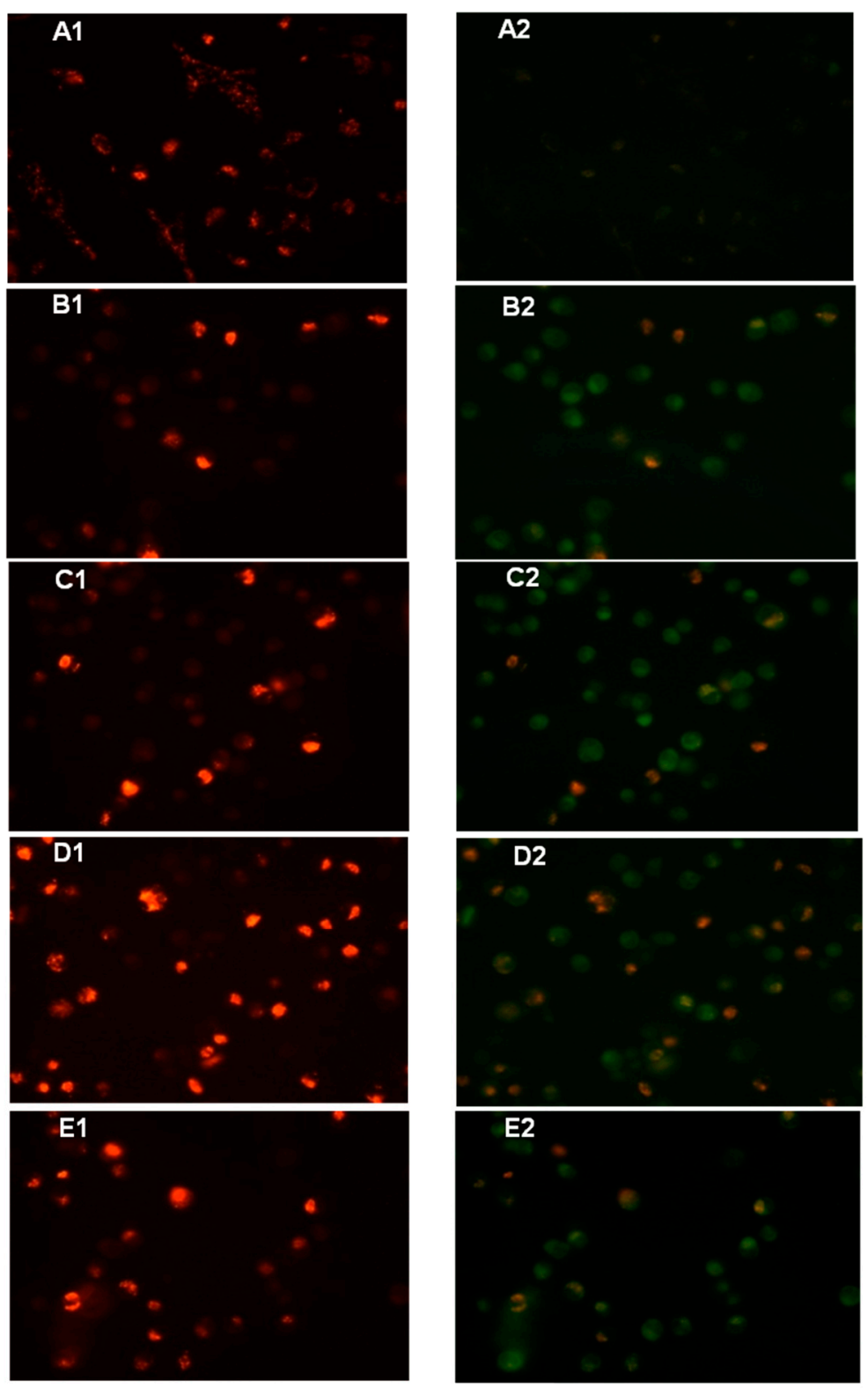
Figure 4. Cont.

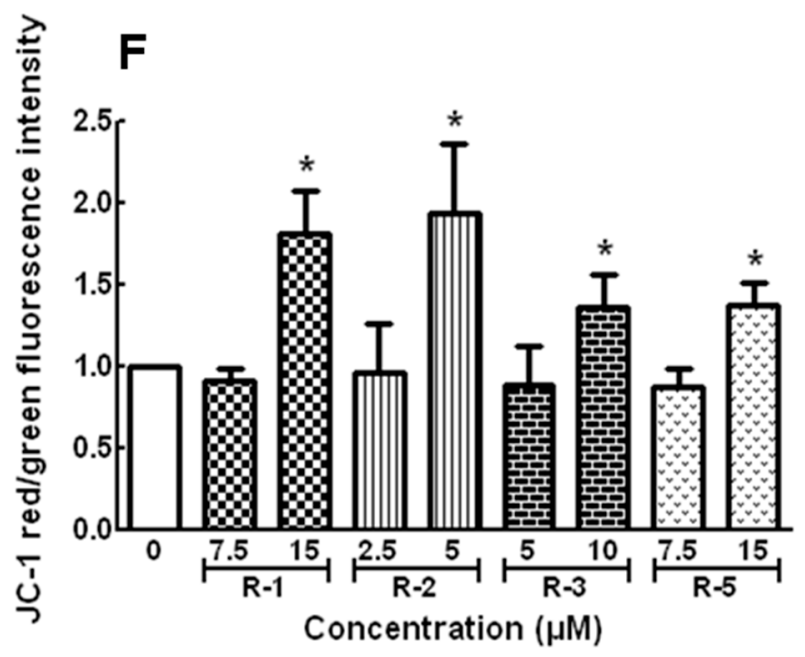

These four polyynes did not exhibit significant effects in the G-phase. Therefore, we regard that induction of apoptosis and cell cycle arrest by OHR-1, -2, $\mathbf{- 3}$ and $\mathbf{- 5}$ contributed to their anti-proliferative effects on MM-231 cells. Acetylated polyynes have the same mechanism as non-acetylated polyynes in the anti-proliferative activity on the cancer cells.

Figure 5. Cell cycle analysis of MDA-MB-231 cells after exposure to OHR-1, -2, $\mathbf{- 3}$ and -5 for $24 \mathrm{~h}$. After treatment, cells were fixed in 70\% ethanol and then analyzed by flow cytometry distribution by propidium iodide/DNA content staining. (A) Solvent controltreated MDA-MB-231 cells; (B1-E1) Cell cycle analysis of cells treated with OHR-1 (7.5 $\mu \mathrm{M})$, OHR-2 $(2.5 \mu \mathrm{M})$, OHR-3 $(5 \mu \mathrm{M})$ and OHR-5 $(7.5 \mu \mathrm{M})$ for; (B2-E2): Cell cycle analysis of cells treated with OHR-1 $(15 \mu \mathrm{M})$, OHR-2 $(5 \mu \mathrm{M}), \mathbf{O H R}-3(10 \mu \mathrm{M}), \mathbf{O H R}-5$ (15 $\mu \mathrm{M})$ treated MDA-MB-231 cells. (F) Cell cycle analysis of MDA-MB-231 cells treated with OHR-1, $\mathbf{- 2 , - 3}$ and $\mathbf{- 5}$ measured by flow cytometry. ${ }^{*} p<0.05$ vs. vehicle control.
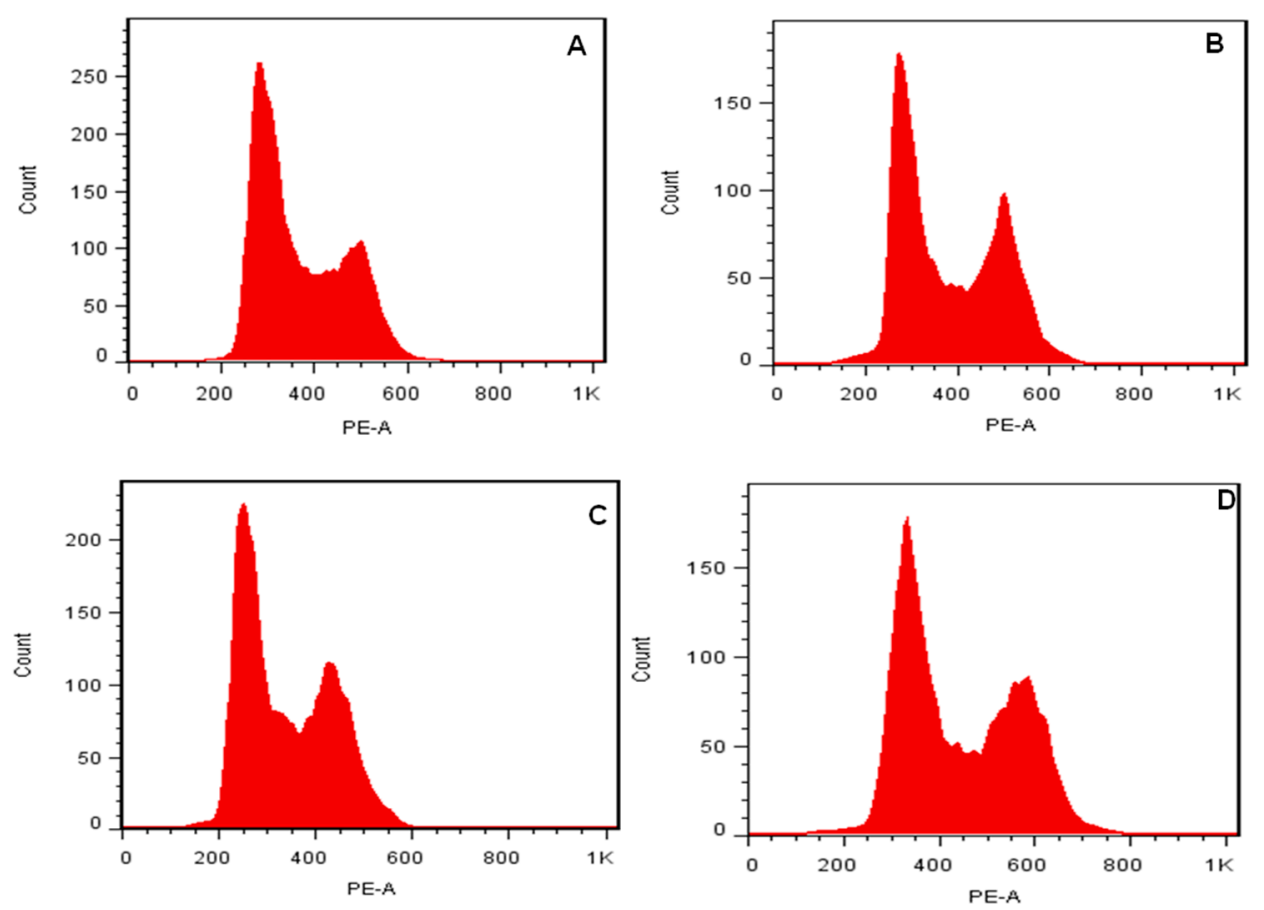
Figure 5. Cont.
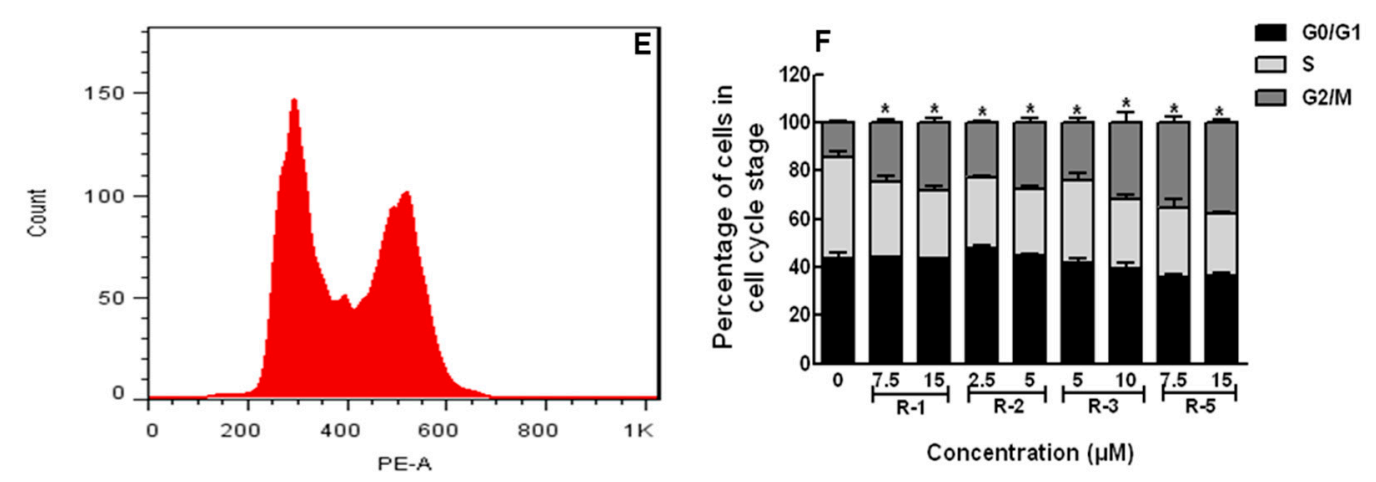

For this investigation, six polyynes and 16 acetylated polyynes were evaluated for their anticancer activities toward selected human cancer lines. OH-1, which has 17 carbon atoms in the main chain with no acetyl group and a terminal ethenyl group, showed the highest anticancer activities in all tested cell lines. This study also suggested that polyynes from $O$. horridus may possibly be active anticancer ingredients.

\section{Experimental Section}

\subsection{General Procedures}

Optical rotations were recorded on a Perkin Elmer Model 341 polarimeter. UV spectrum was measured on a Beckman Coulter DU 640 spectrophotometer. IR spectra were obtained with a PerkinElmer Spectrum 100 FT-IR spectrometer with $\mathrm{KBr}$ pallets. The ${ }^{1} \mathrm{H}-,{ }^{13} \mathrm{C}-$, and $2 \mathrm{D}-\mathrm{NMR}$ spectra were tested on a Bruker AV-500 spectrometer ( $\delta$ in ppm, $J$ in Hz) with tetramethylsilane (TMS) as an internal standard (Bruker, Germany). ESI-MS and HR-ESI-MS measurements were carried out on an Agilent 1100 series LC/MSD Trap VL mass spectrometer and an Agilent time-of-flight (TOF) mass spectrometer respectively (Agilent, Santa Clara, CA, USA). Silica gel (100-200 and 200-300 mesh) (Qingdao Haiyang Chemical Co. Ltd, Qingdao, China) and Merck Reversed-phase $\mathrm{C}_{18}$ (RP-C 18 ) silica gel (40-75 $\mu \mathrm{m})$ (Merck, Darmstadt, Germany) were used for column chromatography (CC). Precoated silica gel $\mathrm{GF}_{254}$ plates (Qingdao Haiyang Chemical Co. Ltd, Qingdao, China) were used for TLC. Supercritical fluid extraction was manipulated on a supercritical fluid extractor (SFT-250, Thar Instruments, Inc., Pittsburgh, PA, USA). Analytical HPLC was performed on an Agilent 1200 liquid chromatograph with an Agilent Zorbax SB RP-C18 column (250 mm $\times 4.6 \mathrm{~mm}$ inside diameter (I.D.), 5 $\mu \mathrm{m}$, Agilent). Preparative HPLC was carried out with an Agilent 1100 liquid chromatograph with a Phenomenex Luna RP-C18 column $(250 \mathrm{~mm} \times 21.2 \mathrm{~mm}$ I.D., $5 \mu \mathrm{m})$.

\subsection{Plant Material}

The dried roots bark of $O$. horridus was obtained from Pacific Botanicals Co. Ltd (Chicago, IL, USA) and authenticated by one of the authors (C.-Z. Wang) in March, 2012. A voucher specimen (Lot: OHR20120926-1) has been deposited in the Institute of Clinical Pharmacology, Central South University, Hunan Province, China. 


\subsection{Chemicals}

HPLC-grade methanol and acetonitrile were purchased from Merck. The deionized water used for HPLC was purified by a Milli-Q purification system (Millipore, Billerica, MA, USA). Chloroform, Methanol and Ethyl acetate (analytical grade) was obtained from Beijing Chemical Reagent Plant (Beijing, China). All the liquid and solid reagents were purchased from Sigma (St. Louis, MO, USA).

\subsection{Extraction and Isolation}

The roots bark of $O$. horridus $(7.2 \mathrm{~kg})$ was sieved by a 20 mesh crib after pulverization. Methanol $(360 \mathrm{~L})$ was selected to extract the pulverized powder with infusion for 7 days $\times 3$. Then, the methanol extract $(900 \mathrm{~g})$ was diffused into pure water $(2 \mathrm{~L})$ and extracted with ethyl acetate (EtOAc) and $n$-butanol to yield the corresponding fractions E (312 g) and B (320 g), respectively. The two organic solvents were used for extraction with the volume of $3 \mathrm{~L} \times 3$, resp., after which were saturated using pure water. The EtOAc-soluble fraction E (260 g) was separated by silica gel (100-200 mesh) column chromatography $(\mathrm{CC})$ eluted with a gradient of $\mathrm{CHCl}_{3}-\mathrm{MeOH}(50: 1$ to $0: 1)$ to give ten fractions (E1-E10). Fraction E7 (53 g) was then subjected to silica gel (200-300 mesh) CC eluting with $\mathrm{CHCl}_{3}-\mathrm{MeOH}(10: 1,8: 1$ and 5:1) to give six subfractions (E7a-E7f). Subfraction E7d (38 g) was chromatographed on $\mathrm{RP}-\mathrm{C}_{18}$ silica gel $\left(\mathrm{MeOH}-\mathrm{H}_{2} \mathrm{O}, 70: 30\right)$, then subjected to Prep-HPLC $\left(\mathrm{MeOH}-\mathrm{H}_{2} \mathrm{O}\right.$, 78:22) to afford OH-1 (1.2 g) and OH-2 (2.4 g). Fraction E8 (75 g) was subjected to silica gel (200-300 mesh) CC eluted with $\mathrm{CHCl}_{3}-\mathrm{MeOH}(10: 1,6: 1$ and 4:1) to afford five subfractions (E8a-E8e). Subfraction E8d (45 g) was chromatographed on $\mathrm{RP}-\mathrm{C}_{18}$ silica gel $\left(\mathrm{MeOH}-\mathrm{H}_{2} \mathrm{O}, 67: 33\right)$, then repeatedly purified by prep-HPLC (MeOH- $\left.\mathrm{H}_{2} \mathrm{O}, 70: 30\right)$ to afford $\mathbf{O H}-3$ (2.9 g) and $\mathbf{O H}-4$ (3.2 g). Subfraction E9 $(68 \mathrm{~g})$ was further separated by $\mathrm{CC}$ on silica gel (200-300 mesh) eluted with $\mathrm{CHCl}_{3}-\mathrm{MeOH}(8: 1,5: 1$ and 3:1) to yield six subfractions (E9a-E9f). Subfraction E9e (36 g) was further purified by prep-HPLC (MeOH- $\left.\mathrm{H}_{2} \mathrm{O}, 65: 35\right)$ to afford OH-5 (1.8 g) and OH-6 (2.1 g).

\subsection{Synthesis of Acetylated Polyynes}

A common acetylation method was used. Acetylated polyynes OHR-1 $\sim$ OHR-16 were synthesized by mixing the subfractions E7d (7.5 g), E8d (7.8 g) and E9e (7.8 g) with acetic anhydride (60 mmol) and $\mathrm{Na}_{2} \mathrm{CO}_{3}(6.36 \mathrm{~g})$ in ethyl acetate $(20 \mathrm{~mL})$, respectively. The reaction mixture was refluxed for $2 \mathrm{~h}$ at $60{ }^{\circ} \mathrm{C}$ while the progress of each reaction was monitored by TLC and HPLC. After quenching the reaction, the mixture was cooled to room temperature and evaporated to remove organic solvents under diminished pressure at $50{ }^{\circ} \mathrm{C}$. The residue was diluted with $\mathrm{H}_{2} \mathrm{O}(50 \mathrm{~mL})$ and each one was extracted with $\mathrm{CHCl}_{3}(40 \mathrm{~mL} \times 3)$. The $\mathrm{CHCl}_{3}$ layer was evaporated and the acetylated products were subjected to chromatographic separation to obtain polyyne derivatives OHR-1 OHR-16 in different yields. Repeated pre-HPLC separation afforded the pure products.

After the subfraction $\mathrm{E} 7 \mathrm{~d}(7.5 \mathrm{~g})$ reacted with acetic anhydride, all the reactants and reaction products were subjected to RP-C $\mathrm{C}_{18}$ silica gel CC $\left(\mathrm{MeOH}-\mathrm{H}_{2} \mathrm{O}, 70: 30 \sim 100: 0\right)$ to obtain four subfractions (E7dR1E7dR4). Subfraction E7dR4 (2.0 g) was purified by prep-HPLC (acetonitrile- $\mathrm{H}_{2} \mathrm{O}, 80: 20$ ) to give OHR1 (200 mg) and OHR-2 (150 mg). Subfraction E7dR3 (880 mg) was purified by prep-HPLC (acetonitrile- 
$\left.\mathrm{H}_{2} \mathrm{O}, 77: 23\right)$ to yield OHR-3 (52 mg) and OHR-4 (50 mg). Subfraction E7dR2 was further purified by prep-HPLC (acetonitrile- $\mathrm{H}_{2} \mathrm{O}, 75: 25$ ) to obtain OHR-5 (28 mg) and OHR-6 (42 mg).

After the reaction between $\mathrm{E} 8 \mathrm{~d}(7.8 \mathrm{~g})$ and acetic anhydride was finished, the condensate was separated by $\mathrm{RP}-\mathrm{C}_{18}$ silica gel $\mathrm{CC}\left(\mathrm{MeOH}-\mathrm{H}_{2} \mathrm{O}, 65: 35 \sim 100: 0\right)$ to afford five subfractions (E8dR1 E8dR5). Subfraction E8dR5 (1.8 g) was purified by prep-HPLC (acetonitrile- $\mathrm{H}_{2} \mathrm{O}$, 78:22) to yield OHR-7 (180 mg) and OHR-8 (170 mg). Subfraction E8dR4 (752 mg) was subjected to prep-HPLC (acetonitrile- $\left.\mathrm{H}_{2} \mathrm{O}, 74: 26\right)$ to afford OHR-9 (112 mg) and OHR-10 (126 mg). Subfraction E8dR3 (610 mg) was separated by prep-HPLC (acetonitrile- $\left.\mathrm{H}_{2} \mathrm{O}, 70: 30\right)$ to afford OHR-11 (36 mg) and OHR-12 (82 mg).

The subfraction E9e (9.2 g) was quenched after reaction with acetic anhydride, then the condensate was chromatographed on $\mathrm{RP}-\mathrm{C}_{18}$ silica gel $\left(\mathrm{MeOH}-\mathrm{H}_{2} \mathrm{O}, 55: 45 \sim 100: 0\right)$ to give six subfractions (E9eR1 E9eR5). Subfraction E9eR3 (720 mg) was purified by prep-HPLC (acetonitrile- $\left.\mathrm{H}_{2} \mathrm{O}, 58: 42\right)$ to afford OHR-13 (24 mg) and OHR-14 (35 mg). Subfraction E9eR2 (400 mg) was separated by prep-HPLC (acetonitrile- $\left.\mathrm{H}_{2} \mathrm{O}, 50: 50\right)$ to afford OHR-15 (12 mg) and OHR-16 (24 mg).

\subsection{Chemical Characteristics of Compounds OH-1 OH-6 and OHR-1 OHR-16}

(3S,8S,Z)-Heptadeca-1,9-dien-4,6-diyne-3,8-diol ((3S,8S)-falcarindiol) OH-1): yellowish oil (1.6 g); $[\alpha]_{\mathrm{D}}^{25}+213.5^{\circ}\left(c=0.36, \mathrm{CHCl}_{3}\right) ; \mathrm{UV}\left(\mathrm{CHCl}_{3}\right) \lambda \max (\log \xi): 217(0.81), 243$ (1.39), 260 (1.75) and 286 (2.11) nm; IR (KBr) vmax: 3345, 3020, 2932, 2850, 2251, 1466, 1021, 938 and $875 \mathrm{~cm}^{-1}$; ${ }^{1} \mathrm{H}-\mathrm{NMR}$ $\left(500 \mathrm{MHz}, \mathrm{CDCl}_{3}\right): \delta_{\mathrm{H}} 0.88(3 \mathrm{H}, \mathrm{t}, 7.0, \mathrm{H}-17), 1.28$ (8H, m, H-13, H-14, H-15, H-16), 1.38 (2H, m, H-12), 2.10 (2H, q, 7.0, H-11), $4.94(1 \mathrm{H}$, brd, $5.0 \mathrm{~Hz}, \mathrm{H}-3), 5.20(1 \mathrm{H}, \mathrm{d}, 8.5 \mathrm{~Hz}, \mathrm{H}-8), 5.25(1 \mathrm{H}, \mathrm{d}, 10.0$ Hz, H-1a), 5.46 (1H, ddt, 11.5, 7.5, $1.0 \mathrm{~Hz}, \mathrm{H}-10), 5.50$ (1H, ddt, 11.5, 5.0, $1.5 \mathrm{~Hz}, \mathrm{H}-9), 5.62(1 \mathrm{H}, \mathrm{dd}$, 17.5, $1.5 \mathrm{~Hz}, \mathrm{H}-1 \mathrm{~b}), 5.92(1 \mathrm{H}, \mathrm{ddd}, 17.5,10.0,6.0 \mathrm{~Hz}, \mathrm{H}-2) .{ }^{13} \mathrm{C}-\mathrm{NMR}\left(125 \mathrm{MHz}, \mathrm{CDCl}_{3}\right): \delta \mathrm{c} 14.0(\mathrm{C}-$ 17), 22.6 (C-15), 27.6 (C-11), 29.0 (C-12), 29.1 (C-14), 29.2(C-13), 31.7(C-16), 58.4 (C-8), 63.3 (C-3), 68.6 (C-6), 70.2 (C-5), 78.3 (C-4), 79.8 (C-7), 117.2 (C-1), 127.6 (C10), 134.4 (C-9), 135.8 (C-2).

(3S,8S,Z)-Heptadeca-9-en-4,6-diyne-3,8-diol (oplopandiol, OH-2): yellowish oil (2.5 g); $[\alpha]_{\mathrm{D}}^{25}+208.6^{\circ}$ $\left(c=0.28, \mathrm{CHCl}_{3}\right) ; \mathrm{UV}\left(\mathrm{CHCl}_{3}\right) \lambda \max (\log \xi): 210(1.25), 245$ (1.39), 253 (2.35) and 267 (4.12) nm; IR (KBr) vmax: 3350, 3015, 2934, 2860, 2250, 1468, 1025, 940 and $866 \mathrm{~cm}^{-1}$; ${ }^{1} \mathrm{H}-\mathrm{NMR}\left(500 \mathrm{MHz}, \mathrm{CDCl}_{3}\right)$ : $\delta_{\mathrm{H}} 0.88(3 \mathrm{H}, \mathrm{t}, 7.0 \mathrm{~Hz}, \mathrm{H}-17), 1.00(3 \mathrm{H}, \mathrm{t}, 7.5 \mathrm{~Hz}, \mathrm{H}-1), 1.28$ (8H, m, H-13, H-14, H-15, H-16), $1.38(2 \mathrm{H}$, m, H-12), 1.73 (2H, m, H-2), 2.09 (2H, q, 7.0 Hz, H-11), 4.38 (1H, t, 6.5 Hz, H-3), 5.19 (1H, d, 8.5 Hz, $\mathrm{H}-8), 5.51(1 \mathrm{H}, \mathrm{t}, 8.5 \mathrm{~Hz}, \mathrm{H}-10), 5.59$ (1H, ddt, 11.0, 7.5, $1.0 \mathrm{~Hz}, \mathrm{H}-9) .{ }^{13} \mathrm{C}-\mathrm{NMR}\left(125 \mathrm{MHz}, \mathrm{CDCl}_{3}\right)$ :

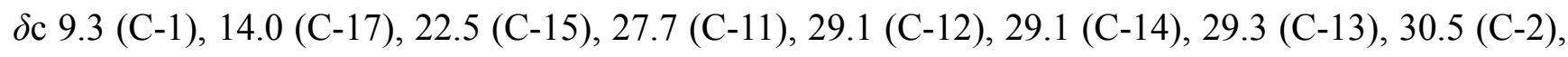
31.7 (C-16), 58.40 (C-8), 63.9 (C-3), 68.7 (C-6), 68.8 (C-5), 79.1 (C-4), 80.7 (C-7), 127.7 (C-10), 134.3 (C-9).

(11S,16S,Z)-11,16-Dihydroxyoctadeca-9,17-dien-12,14-diynyl acetate (OH-3): yellowish oil (2.6 g); $[\alpha]_{\mathrm{D}}^{25}+180.8^{\circ}\left(c=0.53, \mathrm{CHCl}_{3}\right) ; \mathrm{UV}\left(\mathrm{CHCl}_{3}\right) \lambda \max (\log \xi): 206(1.76), 235(1.79), 248(2.89)$ and 268 (4.42) nm; IR (KBr) v $v_{\max }$ 3410, 2920, 2856, 2246, 1718, 1628, 1560, 1465 and $1025 \mathrm{~cm}^{-1}$; ${ }^{1} \mathrm{H}-\mathrm{NMR}$ (500 MHz, CDCl 3 ): $\delta_{\mathrm{H}} 1.30$ (8H, m, H-3, H-4, H-5, H-6), 1.38 (2H, m, H-7), 1.62 (2H, m, H-2), 2.05 (3H, s, COCH3), 2.10 (2H, q, 7.5 Hz, H-8), 4.06 (2H t, 7.5 Hz, H-1), 4.94 (1H, brd, 5.0 Hz, H-16), 5.19 $(1 \mathrm{H}, \mathrm{d}, 8.0 \mathrm{~Hz}, \mathrm{H}-11), 5.24$ (1H, d, $10.5 \mathrm{~Hz}, \mathrm{H}-18 \mathrm{a}), 5.46$ (1H, dd, 17.0, $1.5 \mathrm{~Hz}, \mathrm{H}-18 \mathrm{~b}), 5.51$ (1H, dd, 
10.5, 8.0 Hz, H-9), 5.59 (1H, ddt, 10.5, 7.5, 1.0Hz, H-10), 5.93 (1H, ddd, 17.0, 10.5, $1.5 \mathrm{~Hz}, \mathrm{H}-17)$. ${ }^{13} \mathrm{C}-\mathrm{NMR}\left(125 \mathrm{MHz}, \mathrm{CDCl}_{3}\right): \delta \mathrm{c} 20.9\left(\mathrm{COCH}_{3}\right), 25.7$ (C-2), $27.5(\mathrm{C}-3), 28.5(\mathrm{C}-5), 28.9(\mathrm{C}-4), 29.0(\mathrm{C}-$ 6), 29.1 (C-8), 29.1 (C-7), 58.4 (C-11), 63.2 (C-16), 64.7 (C-1), 68.6 (C-13), 70.0 (C-14), 78.4 (C-15), 80.7 (C-12), 117.0 (C-18), 127.9 (C-10), 134.1 (C-9), 135.9 (C-17), $171.6(\mathrm{C}=\mathrm{O})$.

(11S, 16S,Z)-11,16-Dihydroxyoctadeca-9-en-12,14-diynyl acetate (OH-4): yellowish oil (3.0 g); $[\alpha]_{\mathrm{D}}^{25}+168.8^{\circ}\left(c=0.47, \mathrm{CHCl}_{3}\right) ; \mathrm{UV}\left(\mathrm{CHCl}_{3}\right) \lambda \max (\log \xi): 205$ (1.88), 233 (1.89), 246 (3.39) and 266 (4.05) nm; IR (KBr) v $v_{\max }$ 3440, 2930, 2855, 2250, 1720, 1622, 1550, 1286 and $1020 \mathrm{~cm}^{-1}$; ${ }^{1} \mathrm{H}-\mathrm{NMR}$ (500 MHz, $\left.\mathrm{CDCl}_{3}\right): \delta_{\mathrm{H}} 1.00(3 \mathrm{H}, \mathrm{t}, 7.5 \mathrm{~Hz}, \mathrm{H}-18), 1.30$ (8H, m, H-3, H-4, H-5, H-6), 1.38 (2H, m, H-7), 1.62 (2H, m, H-2), 1.73 (2H, m, H-17), $2.05\left(3 \mathrm{H}, \mathrm{s}, \mathrm{COCH}_{3}\right), 2.11(2 \mathrm{H}, \mathrm{q}, 7.5 \mathrm{~Hz}, \mathrm{H}-8), 4.05$ (2H, t, $7.0 \mathrm{~Hz}, \mathrm{H}-1), 4.37(1 \mathrm{H}, \mathrm{t}, 6.5 \mathrm{~Hz}, \mathrm{H}-16), 5.18(1 \mathrm{H}, \mathrm{d}, 8.5 \mathrm{~Hz}, \mathrm{H}-11), 5.50$ (1H, ddt, 10.6, 7.5, $1.5 \mathrm{~Hz}$, H-9), 5.58 (1H, ddt, 10.6, 8.5, $1.5 \mathrm{~Hz}, \mathrm{H}-10) .{ }^{13} \mathrm{C}-\mathrm{NMR}\left(125 \mathrm{MHz}, \mathrm{CDCl}_{3}\right): \delta \mathrm{c} 9.3(\mathrm{C}-18), 21.0\left(\mathrm{COCH}_{3}\right)$, 25.7 (C-2), 27.5 (C-8), 28.9 (C-6), 28.9 (C-5), 29.0 (C-4), 29.1 (C-3), 29.1 (C-7), 30.5 (C-17), 58.4 (C-11), 64.7 (C-16), 68.6 (C-1), 68.7 (C-13), 70.0 (C-14), 79.1 (C-15), 80.7 (C-12), 127.9 (C-10), 134.0 (C-9), $171.6(\mathrm{C}=\mathrm{O})$.

(11S,16S,Z)-Octadeca-9,17-dien-12,14-diyne-1,11,16-triol (oplopantriol A, OH-5): yellowish oil (1.8 g); $[\alpha]_{\mathrm{D}}^{25}+194.4^{\circ}\left(c=0.16, \mathrm{CHCl}_{3}\right) ; \mathrm{UV}\left(\mathrm{CHCl}_{3}\right) \lambda \max (\log \xi): 226(1.10), 255$ (4.09) and $261(3.95) \mathrm{nm} ;$ IR (KBr) vmax: 3357, 3022, 2929, 2855, 2251, 2150, 1675, 1405 and1303 cm ${ }^{-1} .{ }^{1} \mathrm{H}-\mathrm{NMR}(500 \mathrm{MHz}$, $\left.\mathrm{CDCl}_{3}\right): \delta_{\mathrm{H}} 1.31$ (8H, m, H-3, H-4, H-5, H-6), 1.39 (2H, m, H-7), 1.56 (2H, m, H-2), 2.11 (2H, dq, 1.5, $7.5 \mathrm{~Hz}, \mathrm{H}-8), 3.64$ (2H, t, 7.0 Hz, H-1), 4.93 (1H, brd, $5.5 \mathrm{~Hz}, \mathrm{H}-16), 5.19$ (1H, d, 8.0 Hz, H-11), 5.22 $(1 \mathrm{H}, \mathrm{dt}, 10.0,1.0 \mathrm{~Hz}, \mathrm{H}-18 \mathrm{a}), 5.46(1 \mathrm{H}, \mathrm{dt}, 17.4,1.0 \mathrm{~Hz}, \mathrm{H}-18 \mathrm{~b}), 5.51$ (1H, ddt, 10.6, 8.2, $1.5 \mathrm{~Hz}, \mathrm{H}-9)$, $5.58(1 \mathrm{H}, \mathrm{ddt}, 10.6,7.3,1.5 \mathrm{~Hz}, \mathrm{H}-10), 5.93(1 \mathrm{H}, \mathrm{ddd}, 17.4,10.0,5.5 \mathrm{~Hz}, \mathrm{H}-17) .{ }^{13} \mathrm{C}-\mathrm{NMR}(125 \mathrm{MHz}$, $\mathrm{CDCl}_{3}$ ): $\delta \mathrm{c} 25.6$ (C-3), 27.5 (C-8), 28.8 (C-7), 29.0 (C-6), 29.1 (C-4), 29.2 (C-5), 32.6 (C-2), 58.5 (C-11), 63.0 (C-1), 63.3 (C-16), 68.7 (C-13), 70.1 (C-14), 78.5 (C-15), 79.8 (C-12), 117.1 (C-18), 127.9 (C-9), 134.2 (C-10), 136.0 (C-17).

(11S,16S,Z)-Octadeca-9-en-12,14-diyne-1,11,16-triol (oplopantriol B, OH-6): yellowish oil (2.5 g); $[\alpha]_{\mathrm{D}}^{25}+233.0^{\circ}\left(c=0.3, \mathrm{CHCl}_{3}\right) ; \mathrm{UV}\left(\mathrm{CHCl}_{3}\right) \lambda \max (\log \xi): 207$ (1.07), 232 (1.17), 263 (3.98), and 288 (3.84) nm; IR (KBr) $v_{\max }$ : 3355, 3021, 2930, 2856, 2232, 2143, 1656, 1463, 1305, 1095 and $1017 \mathrm{~cm}^{-1}$; ${ }^{1} \mathrm{H}-\mathrm{NMR}\left(500 \mathrm{MHz}, \mathrm{CDCl}_{3}\right): \delta_{\mathrm{H}} 1.00(3 \mathrm{H}, \mathrm{s}, \mathrm{H}-18), 1.74$ (2H, m, H-17), 1.31 (8H, m, H-3, H-4, H-5, H6), 1.38 (2H, m, H-7), 1.57 (2H, m, H-2), 2.11 (2H, dq, 1.5, 7.1 Hz, H-8), 3.64 (2H, t, 6.5 Hz, H-1), 4.37 $(1 \mathrm{H}, \mathrm{t}, 6.6 \mathrm{~Hz}, \mathrm{H}-16), 5.19(1 \mathrm{H}, \mathrm{d}, 8.0 \mathrm{~Hz}, \mathrm{H}-11), 5.52$ (1H, ddt, 10.6, 7.5, $1.5 \mathrm{~Hz}, \mathrm{H}-9), 5.58$ (1H, ddt, 10.6, 7.3, $1.5 \mathrm{~Hz}, \mathrm{H}-10) .{ }^{13} \mathrm{C}-\mathrm{NMR}\left(125 \mathrm{MHz}, \mathrm{CDCl}_{3}\right)$ : $\delta \mathrm{c} 9.3(\mathrm{C}-18), 25.6(\mathrm{C}-2), 27.5(\mathrm{C}-8), 28.8(\mathrm{C}-$ 7), 29.0 (C-6), 29.1 (C-4), 29.2 (C-5), 30.6 (C-17), 32.6 (C-2), 58.5 (C-11), 63.0 (C-1), 63.8 (C-16), 68.8 (C-13), 68.8 (C-14), 80.9 (C-15), 79.1 (C-12), 128.0 (C-19), 134.1 (C-10).

(3S,8S,Z)-Heptadeca-9-en-4, 6-diyne-3,8-diyl diacetate (OHR-1): yellowish oil (210 mg); $[\alpha]_{\mathrm{D}}^{25}+202.8^{\circ}$ $\left(c=0.86, \mathrm{CHCl}_{3}\right) ; \mathrm{UV}\left(\mathrm{CHCl}_{3}\right) \lambda \max (\log \xi): 206$ (1.27), 232 (1.37), 253 (3.73), and 267 (4.12) nm; IR (KBr) $v_{\max }: 3012,2920,2816,2248,1726,1718,1612,1436,1252,1068$ and $930 \mathrm{~cm}^{-1}$; ${ }^{1} \mathrm{H}-\mathrm{NMR}$ (500 MHz, $\left.\mathrm{CDCl}_{3}\right): \delta_{\mathrm{H}} 0.88(3 \mathrm{H}, \mathrm{t}, 7.0, \mathrm{H}-17), 1.00(3 \mathrm{H}, \mathrm{t}, 7.0, \mathrm{H}-1), 1.28(8 \mathrm{H}, \mathrm{m}, \mathrm{H}-13, \mathrm{H}-14, \mathrm{H}-15, \mathrm{H}-$ 16), 1.38 (2H, m, H-12), 1.79 (2H, m, H-2), 2.07 (6H, s, $\left.\mathrm{COCH}_{3}\right) 2.13$ (2H, dq, 7.0, $\left.1.0 \mathrm{~Hz}, \mathrm{H}-11\right), 5.33$ $(1 \mathrm{H}, \mathrm{t}, 6.5 \mathrm{~Hz}, \mathrm{H}-3), 5.46$ (1H, ddt, 11.0, 8.5, $1.5 \mathrm{~Hz}, \mathrm{H}-9), 5.66$ (1H, dt, 11.0, 7.5, $1.0 \mathrm{~Hz}, \mathrm{H}-10), 6.11$ 
(1H, dt, 8.5, 1.0 Hz, H-8). ${ }^{13} \mathrm{C}-\mathrm{NMR}\left(125 \mathrm{MHz}, \mathrm{CDCl}_{3}\right): \delta \mathrm{c} 9.2(\mathrm{C}-1), 14.0(\mathrm{C}-17), 20.8\left(\mathrm{COCH}_{3}\right), 20.9$ $\left(\mathrm{COCH}_{3}\right), 22.6$ (C-15), 27.8 (C-11), 27.8 (C-12), 29.1 (C-14), 29.1 (C-13), 29.2 (C-2), 31.7 (C-16), 60.1 (C-8), 65.2 (C-3), 69.2 (C-6), 69.3 (C-5), 76.0 (C-4), 77.3 (C-7), 123.8 (C-10), 136.4 (C-9), 169.4 (C=O), $169.7(\mathrm{C}=\mathrm{O})$.

(3S, 8S,Z)-Heptadeca-1,9-dien-4,6-diyne-3,8-diyl diacetate (OHR-2): yellowish oil (220 mg); $[\alpha]_{\mathrm{D}}^{25}+243.5^{\circ}$ ( $\left.c=0.92, \mathrm{CHCl}_{3}\right)$; $\mathrm{UV}\left(\mathrm{CHCl}_{3}\right) \lambda \max (\log \xi): 208$ (1.07), 228 (1.52), 248 (3.25) and 270 (3.66) nm; IR (KBr) $v_{\max }$ : 2982, 2867, 2248, 1720, 1716, 1384, 1142, 950 and $862 \mathrm{~cm}^{-1} ;{ }^{1} \mathrm{H}-\mathrm{NMR}\left(500 \mathrm{MHz}, \mathrm{CDCl}_{3}\right)$ : $\delta_{\mathrm{H}} 0.88(3 \mathrm{H}, \mathrm{t}, 7.0, \mathrm{H}-17), 1.28$ (8H, m, H-13, H-14, H-15, H-16), 1.36 (2H, m, H-12), 2.07 (3H, s, $\left.\mathrm{COCH}_{3}\right), 2.09\left(3 \mathrm{H}, \mathrm{s}, \mathrm{COCH}_{3}\right), 2.14(2 \mathrm{H}, \mathrm{q}, 7.0, \mathrm{H}-11), 5.33(1 \mathrm{H}, \mathrm{d}, 10.0 \mathrm{~Hz}, \mathrm{H}-1 \mathrm{a}), 5.46(1 \mathrm{H}, \mathrm{ddt}, 10.5$, 8.5, 1.5Hz, H-9), $5.53(1 \mathrm{H}, \mathrm{d}, 17.5 \mathrm{~Hz}, \mathrm{H}-1 \mathrm{~b}), 5.66(1 \mathrm{H}, \mathrm{ddt}, 10.5,7.0,1.0 \mathrm{~Hz}, \mathrm{H}-10), 5.84$ (1H, ddd, 17.5, 10.0, $6.0 \mathrm{~Hz}, \mathrm{H}-2), 5.90(1 \mathrm{H}, \mathrm{dd}, 6.0,1.0 \mathrm{~Hz}, \mathrm{H}-3), 6.13(1 \mathrm{H}, \mathrm{d}, 8.5 \mathrm{~Hz}, \mathrm{H}-8)$. ${ }^{13} \mathrm{C}-\mathrm{NMR}\left(125 \mathrm{MHz}, \mathrm{CDCl}_{3}\right): \delta \mathrm{c} 14.1(\mathrm{C}-17), 20.8\left(\mathrm{COCH}_{3}\right), 20.9\left(\mathrm{COCH}_{3}\right), 22.6(\mathrm{C}-15), 27.9(\mathrm{C}-11)$, 29.0 (C-12), 29.1 (C-14), 29.1 (C-13), 31.8 (C-16), 60.0 (C-8), 64.4 (C-3), 69.1 (C-6), 70.7 (C-5), 75.1 (C-4), 77.6 (C-7), 119.7 (C-1), 123.7 (C-10), 131.9 (C-9), 136.5 (C-2), $169.4(\mathrm{C}=\mathrm{O}), 169.4(\mathrm{C}=\mathrm{O})$.

(3S,8S,Z)-3-Hydroxyheptadeca-9-en-4,6-diyn-8-yl acetate (OHR-3): yellowish oil (60 mg); $[\alpha]_{\mathrm{D}}^{25}+164.6^{\circ}$ $\left(c=0.72, \mathrm{CHCl}_{3}\right) ; \mathrm{UV}\left(\mathrm{CHCl}_{3}\right) \lambda \max (\log \xi): 203$ (0.86), 224 (1.57), 242 (4.21), and 266 (4.58) nm; IR (KBr) $v_{\max }: 3385,3025,2946,2825,2230,1715,1580,1420,1232,1060$ and $896 \mathrm{~cm}^{-1}$; ${ }^{1} \mathrm{H}-\mathrm{NMR}$ $\left(500 \mathrm{MHz}, \mathrm{CDCl}_{3}\right): \delta_{\mathrm{H}} 0.88(3 \mathrm{H}, \mathrm{t}, 7.0, \mathrm{H}-17), 1.00(3 \mathrm{H}, \mathrm{t}, 7.0, \mathrm{H}-1), 1.28(8 \mathrm{H}, \mathrm{m}, \mathrm{H}-13, \mathrm{H}-14, \mathrm{H}-15, \mathrm{H}-$ 16), 1.38 (2H, m, H-12), 1.79 (2H, m, H-2), 2.07 (6H, s, $\left.\mathrm{COCH}_{3}\right) 2.13$ (2H, dq, 7.0, $\left.1.0 \mathrm{~Hz}, \mathrm{H}-11\right), 4.37$ $(1 \mathrm{H}, \mathrm{t}, 6.5 \mathrm{~Hz}, \mathrm{H}-3), 5.47$ (1H, ddt, 11.0, 8.5, 1.5 Hz, H-9), 5.65 (1H, ddt, 11.0, 7.5, 1.0 Hz, H-10), 6.13 $(1 \mathrm{H}, \mathrm{d}, 8.5 \mathrm{~Hz}, \mathrm{H}-8) .{ }^{13} \mathrm{C}-\mathrm{NMR}\left(125 \mathrm{MHz}, \mathrm{CDCl}_{3}\right): \delta \mathrm{c} 9.2(\mathrm{C}-1), 14.0(\mathrm{C}-17), 20.9\left(\mathrm{COCH}_{3}\right), 22.6(\mathrm{C}-$ 15), 27.8 (C-11), 27.8 (C-12), 29.1 (C-14), 29.2 (C-13), 30.6 (C-2), 31.7 (C-16), 60.1 (C-8), 64.0 (C-3), 68.9 (C-6), 69.4 (C-5), 75.9 (C-4), 80.9 (C-7), 123.9 (C-10), 136.3 (C-9), 169.5 (C=O).

(3S,8S,Z)-8-Hydroxyheptadeca-9-en-4,6-diyn-3-yl acetate (OHR-4): yellowish oil (55 mg); $[\alpha]_{\mathrm{D}}^{25}+213.6^{\circ}$ $\left(c=1.12, \mathrm{CHCl}_{3}\right) ; \mathrm{UV}\left(\mathrm{CHCl}_{3}\right) \lambda \max (\log \xi): 205$ (0.93), 222 (2.17), 245 (4.01), and 270 (4.27) nm; IR (KBr) $v_{\max }: 3360,3010,2936,2860,2252,1722,1596,1440,1210,1060$ and $912 \mathrm{~cm}^{-1}$; ${ }^{1} \mathrm{H}-\mathrm{NMR}$ $\left(500 \mathrm{MHz}, \mathrm{CDCl}_{3}\right): \delta_{\mathrm{H}} 0.88(3 \mathrm{H}, \mathrm{t}, 7.0, \mathrm{H}-17), 1.02(3 \mathrm{H}, \mathrm{t}, 7.0, \mathrm{H}-1), 1.28$ (8H, m, H-13, H-14, H-15, $\mathrm{H}-16), 1.38$ (2H, m, H-12), 1.79 (2H, m, H-2), $2.07\left(3 \mathrm{H}, \mathrm{s}, \mathrm{COCH}_{3}\right) 2.13(2 \mathrm{H}, \mathrm{dq}, 7.0,1.0 \mathrm{~Hz}, \mathrm{H}-11)$, $5.19(1 \mathrm{H}, \mathrm{d}, 8.0 \mathrm{~Hz}, \mathrm{H}-8), 5.34(1 \mathrm{H}, \mathrm{t}, 6.5 \mathrm{~Hz}, \mathrm{H}-3), 5.48(1 \mathrm{H}, \mathrm{ddt}, 11.0,8.5,1.5 \mathrm{~Hz}, \mathrm{H}-9), 5.63(1 \mathrm{H}, \mathrm{dt}$, 11.0, 7.5, $1.0 \mathrm{~Hz}, \mathrm{H}-10) .{ }^{13} \mathrm{C}-\mathrm{NMR}\left(125 \mathrm{MHz}, \mathrm{CDCl}_{3}\right): \delta \mathrm{c} 9.2(\mathrm{C}-1), 14.0(\mathrm{C}-17), 20.8\left(\mathrm{COCH}_{3}\right), 22.6$ (C-15), 27.7 (C-11), 27.9 (C-12), 29.1 (C-14), 29.2 (C-13), 29.3 (C-2), 31.8 (C-16), 58.7 (C-8), 65.3 (C3), 69.2 (C-6), 69.3 (C-5), 76.0 (C-4), 79.4 (C-7), 127.8 (C-10), 134.7 (C-9), 169.5 (C=O).

(3S,8S,Z)-3-Hydroxyheptadeca-1,9-dien-4,6-diyn-8-yl acetate (OHR-5): yellowish oil (30 mg); [a $]_{\mathrm{D}}^{25}$ $+230.2^{\circ}\left(c=0.91, \mathrm{CHCl}_{3}\right) ; \mathrm{UV}\left(\mathrm{CHCl}_{3}\right) \lambda \max (\log \xi): 210$ (1.56), 228 (3.17), 242 (4.31), and 265 (4.45) nm; IR (KBr) v $v_{\max }: 3422,2981,2258,1716,1584,1432,1226,1030$ and $990 \mathrm{~cm}^{-1}$; ${ }^{1} \mathrm{H}-\mathrm{NMR}(500 \mathrm{MHz}$, $\left.\mathrm{CDCl}_{3}\right): \delta_{\mathrm{H}} 0.89(3 \mathrm{H}, \mathrm{t}, 7.0, \mathrm{H}-17), 1.27(8 \mathrm{H}, \mathrm{m}, \mathrm{H}-13, \mathrm{H}-14, \mathrm{H}-15, \mathrm{H}-16), 1.38(2 \mathrm{H}, \mathrm{m}$, $\mathrm{H}-12), 2.07\left(3 \mathrm{H}, \mathrm{s}, \mathrm{COCH}_{3}\right), 2.14(2 \mathrm{H}, \mathrm{q}, 7.0, \mathrm{H}-11), 4.93(1 \mathrm{H}, \mathrm{d}, 6.0 \mathrm{~Hz}, \mathrm{H}-3), 5.27(1 \mathrm{H}, \mathrm{d}, 10.0 \mathrm{~Hz}$, $\mathrm{H}-1 \mathrm{a}), 5.46(1 \mathrm{H}, \mathrm{ddt}, 10.5,8.5,1.5 \mathrm{~Hz}, \mathrm{H}-9), 5.50(1 \mathrm{H}, \mathrm{d}, 17.5 \mathrm{~Hz}, \mathrm{H}-1 \mathrm{~b}), 5.66(1 \mathrm{H}, \mathrm{ddt}, 10.5,7.0,1.0 \mathrm{~Hz}$, $\mathrm{H}-10), 5.84(1 \mathrm{H}$, ddd, 17.5, 10.0, $6.0 \mathrm{~Hz}, \mathrm{H}-2), 6.14$ (1H, d, $8.5 \mathrm{~Hz}, \mathrm{H}-8) .{ }^{13} \mathrm{C}-\mathrm{NMR}\left(125 \mathrm{MHz}, \mathrm{CDCl}_{3}\right)$ : 
$\delta$ c 14.1 (C-17), $20.9\left(\mathrm{COCH}_{3}\right), 22.6$ (C-15), 27.9 (C-11), 29.0 (C-12), 29.1 (C-14), 29.2 (C-13), 31.8 (C16), 60.0 (C-8), 64.4 (C-3), 69.2 (C-6), 70.9 (C-5), 75.5 (C-4), 77.7 (C-7), 117.4 (C-1), 123.8 (C-10), 131.9 (C-9), 136.5 (C-2), $169.4(\mathrm{C}=\mathrm{O})$.

(3S,8S,Z)-8-Hydroxyheptadeca-1,9-dien-4,6-diyn-3-yl acetate (OHR-6): yellowish oil (45 mg); $[\alpha]_{\mathrm{D}}^{25}$ $+210.8^{\circ}\left(c=0.51, \mathrm{CHCl}_{3}\right) ; \mathrm{UV}\left(\mathrm{CHCl}_{3}\right) \lambda \max (\log \xi): 208$ (1.36), $226(2.57), 248$ (4.31), and 268 (4.48) nm; IR (KBr) vmax: 3380, 3012, 2252, 1718, 1560, 1482, 1216, 1024 and $990 \mathrm{~cm}^{-1}$; ${ }^{1} \mathrm{H}-\mathrm{NMR}(500 \mathrm{MHz}$, $\left.\mathrm{CDCl}_{3}\right): \delta_{\mathrm{H}} 0.89(3 \mathrm{H}, \mathrm{t}, 7.0, \mathrm{H}-17), 1.27(8 \mathrm{H}, \mathrm{m}, \mathrm{H}-13, \mathrm{H}-14, \mathrm{H}-15, \mathrm{H}-16), 1.38(2 \mathrm{H}, \mathrm{m}$, H-12), $2.09\left(3 \mathrm{H}, \mathrm{s}, \mathrm{COCH}_{3}\right), 2.11(2 \mathrm{H}, \mathrm{q}, 7.0, \mathrm{H}-11), 5.19(1 \mathrm{H}, \mathrm{d}, 6.0 \mathrm{~Hz}, \mathrm{H}-3), 5.33(1 \mathrm{H}, \mathrm{d}, 10.0 \mathrm{~Hz}, \mathrm{H}-$ 1a), $5.48(1 \mathrm{H}, \mathrm{ddt}, 10.5,8.5,1.5 \mathrm{~Hz}, \mathrm{H}-9), 5.51(1 \mathrm{H}, \mathrm{d}, 17.5 \mathrm{~Hz}, \mathrm{H}-1 \mathrm{~b}), 5.60(1 \mathrm{H}, \mathrm{ddt}, 10.5,7.0,1.0 \mathrm{~Hz}, \mathrm{H}-$ 10), $5.86(1 \mathrm{H}, \mathrm{ddd}, 17.5,10.0,6.0 \mathrm{~Hz}, \mathrm{H}-2), 5.91(1 \mathrm{H}, \mathrm{d}, 8.5 \mathrm{~Hz}, \mathrm{H}-8) .{ }^{13} \mathrm{C}-\mathrm{NMR}\left(125 \mathrm{MHz}, \mathrm{CDCl}_{3}\right)$ : $\delta$ c $14.0(\mathrm{C}-17), 20.8\left(\mathrm{COCH}_{3}\right), 22.6(\mathrm{C}-15), 27.9(\mathrm{C}-11), 29.0$ (C-12), 29.1 (C-14), $29.2(\mathrm{C}-13), 31.8$ (C16), 58.6 (C-8), 64.4 (C-3), 68.6 (C-6), 70.8 (C-5), 74.8 (C-4), 80.1 (C-7), 119.7 (C-1), 127.6 (C-10), 132.0 (C-9), 134.7 (C-2), $169.4(\mathrm{C}=\mathrm{O})$.

(11S,16S,Z)-Octadeca-9-en-12,14-diyne-1,11,16-triyl triacetate (OHR-7): yellowish oil (180 mg); $[\alpha]_{\mathrm{D}}^{25}+185.4^{\circ}\left(c=0.41, \mathrm{CHCl}_{3}\right) ; \mathrm{UV}\left(\mathrm{CHCl}_{3}\right) \lambda \max (\log \xi): 205$ (0.76), 223 (1.35), 240 (3.21), and 265 (4.05) nm; IR (KBr) v $v_{\max }$ : 2985, 2258, 1723, 1716, 1585, 1477, 1238, 1028 and $954 \mathrm{~cm}^{-1}$; ${ }^{1} \mathrm{H}-\mathrm{NMR}(500$ $\left.\mathrm{MHz}, \mathrm{CDCl}_{3}\right): \delta_{\mathrm{H}} 1.00(3 \mathrm{H}, \mathrm{t}, 7.5 \mathrm{~Hz}, \mathrm{H}-18), 1.29$ (8H, m, H-3, H-4, H-5, H-6), 1.37 (2H, m, $\mathrm{H}-7), 1.61(2 \mathrm{H}, \mathrm{m}, \mathrm{H}-2), 1.79(2 \mathrm{H}, \mathrm{m}, \mathrm{H}-17), 2.04\left(3 \mathrm{H}, \mathrm{s}, \mathrm{COCH}_{3}\right), 2.07\left(6 \mathrm{H}, \mathrm{s}, 2 \times \mathrm{COCH}_{3}\right), 2.13(2 \mathrm{H}$, q, $7.5 \mathrm{~Hz}, \mathrm{H}-8), 4.05(2 \mathrm{H}, \mathrm{t}, 7.0 \mathrm{~Hz}, \mathrm{H}-1), 5.33(1 \mathrm{H}, \mathrm{t}, 6.5 \mathrm{~Hz}, \mathrm{H}-16), 5.47(1 \mathrm{H}$, ddt, 10.6, 7.5, $1.5 \mathrm{~Hz}$, $\mathrm{H}-9), 5.66(1 \mathrm{H}, \mathrm{ddt}, 10.6,8.5,1.5 \mathrm{~Hz}, \mathrm{H}-10), 6.13(1 \mathrm{H}, \mathrm{d}, 8.5 \mathrm{~Hz}, \mathrm{H}-11) .{ }^{13} \mathrm{C}-\mathrm{NMR}\left(125 \mathrm{MHz}, \mathrm{CDCl}_{3}\right)$ : $\delta$ c $9.2(\mathrm{C}-18), 20.8\left(\mathrm{COCH}_{3}\right), 20.9\left(\mathrm{COCH}_{3}\right), 21.0\left(\mathrm{COCH}_{3}\right), 25.8(\mathrm{C}-2), 27.8(\mathrm{C}-8), 28.6(\mathrm{C}-6), 28.9$ (C-5), 29.0 (C-4), 29.1 (C-3), 29.1 (C-7), 29.3 (C-17), 60.0 (C-11), 64.6 (C-16), 65.1 (C-1), 69.2 (C-13), 69.3 (C-14), 75.9 (C-15), 77.2 (C-12), 123.8 (C-10), 136.2 (C-9), $169.4(\mathrm{C}=\mathrm{O}), 169.7(\mathrm{C}=\mathrm{O}), 171.2(\mathrm{C}=\mathrm{O})$.

(11S, 16S,Z)-Octadeca-9,17-dien-12,14-diyne-1,11,16-triyl triacetate (OHR-8): yellowish oil (175 mg); $[\alpha]_{\mathrm{D}}^{25}+236.7^{\circ}\left(c=0.61, \mathrm{CHCl}_{3}\right) ; \mathrm{UV}\left(\mathrm{CHCl}_{3}\right) \lambda \max (\log \xi): 210(1.46), 228(2.15), 246(3.71)$, and 274 (4.65) nm; IR (KBr) $v_{\max }$ : 2968, 2257, 1720, 1718, 1562, 1457, 1318, 1016 and $946 \mathrm{~cm}^{-1}$; ${ }^{1} \mathrm{H}-\mathrm{NMR}(500$ $\mathrm{MHz}_{\mathrm{CDCl}}$ ): $\delta_{\mathrm{H}} 1.29$ (8H, m, H-3, H-4, H-5, H-6), 1.37 (2H, m, H-7), 1.62 (2H, m, H-2), 2.04 (3H, s, $\mathrm{COCH} 3), 2.07$ (3H, s, COCH3), $2.10(3 \mathrm{H}, \mathrm{s}, \mathrm{COCH} 3), 2.13(2 \mathrm{H}, \mathrm{q}, 7.5 \mathrm{~Hz}, \mathrm{H}-8), 4.05(2 \mathrm{H} \mathrm{t}, 7.5 \mathrm{~Hz}, \mathrm{H}-$ 1), $5.33(1 \mathrm{H}, \mathrm{d}, 10.5 \mathrm{~Hz}, \mathrm{H}-18 \mathrm{a}), 5.46(1 \mathrm{H}, \mathrm{dt}, 10.5,7.5 \mathrm{~Hz}, \mathrm{~Hz}, \mathrm{H}-9), 5.53(1 \mathrm{H}, \mathrm{dd}, 17.5,1.5 \mathrm{~Hz}, \mathrm{H}-$ 18b), 5.66 (1H, ddt, 10.5, 7.5, 1.0Hz, H-10), 5.85 (1H, ddd, 17.0, 10.0, 1.5 Hz, H-17), 5.90 (1H, brd, 5.0 $\mathrm{Hz}, \mathrm{H}-16), 6.13(1 \mathrm{H}, \mathrm{d}, 8.0 \mathrm{~Hz}, \mathrm{H}-11) .{ }^{13} \mathrm{C}-\mathrm{NMR}\left(125 \mathrm{MHz}, \mathrm{CDCl}_{3}\right): \delta \mathrm{c} 20.8\left(\mathrm{COCH}_{3}\right), 20.9\left(\mathrm{COCH}_{3}\right)$, $20.9\left(\mathrm{COCH}_{3}\right), 25.8$ (C-2), 27.8 (C-3), 28.6 (C-5), 29.0 (C-4), 29.0 (C-6), 29.1 (C-8), 29.2 (C-7), 60.0 (C-11), 64.3 (C-16), 64.6 (C-1), 69.1 (C-13), 70.7 (C-14), 75.1 (C-15), 76.7 (C-12), 119.7 (C-18), 123.7 (C-10), $131.9(\mathrm{C}-9), 136.3(\mathrm{C}-17), 169.3(\mathrm{C}=\mathrm{O}), 169.4(\mathrm{C}=\mathrm{O}), 171.6(\mathrm{C}=\mathrm{O})$.

(11S, 16S,Z)-16-Hydroxyoctadeca-9,17-dien-12,14-diyne-1,16-diyl diacetate (OHR-9): yellowish oil $(110 \mathrm{mg}) ;[\alpha]_{\mathrm{D}}^{25}+285.2^{\circ}\left(c=1.01, \mathrm{CHCl}_{3}\right) ; \mathrm{UV}\left(\mathrm{CHCl}_{3}\right) \lambda \max (\log \xi): 208$ (1.40), 226 (3.15), 245 (4.81), and $268(4.55) \mathrm{nm}$; IR (KBr) $v_{\max }$ : 3348, 3014, 2988, 2254, 1722, 1710, 1486, 1380, 1258, 1016 and 885 $\mathrm{cm}^{-1}$; ${ }^{1} \mathrm{H}-\mathrm{NMR}\left(500 \mathrm{MHz}, \mathrm{CDCl}_{3}\right): \delta_{\mathrm{H}} 1.29(8 \mathrm{H}, \mathrm{m}, \mathrm{H}-3, \mathrm{H}-4, \mathrm{H}-5, \mathrm{H}-6), 1.37$ (2H, m, H-7), 1.62 (2H, m, H-2), 2.04 (3H, s, COCH3), 2.07 (3H, s, COCH3), 2.13 (2H, q, 7.5 Hz, H-8), 4.05 (2H t, 7.5 Hz, H- 
1), 5.19 (1H, d, 8.0 Hz, H-11), $5.34(1 \mathrm{H}, \mathrm{d}, 10.5 \mathrm{~Hz}, \mathrm{H}-18 \mathrm{a}), 5.50$ (1H, dt, 10.5, 7.5 Hz, Hz, H-9), 5.52 $(1 \mathrm{H}, \mathrm{dd}, 17.5,1.5 \mathrm{~Hz}, \mathrm{H}-18 \mathrm{~b}), 5.62(1 \mathrm{H}, \mathrm{ddt}, 10.5,7.5,1.0 \mathrm{~Hz}, \mathrm{H}-10), 5.86(1 \mathrm{H}$, ddd, 17.0, 10.0, $1.5 \mathrm{~Hz}$, $\mathrm{H}-17), 5.90(1 \mathrm{H}$, brd, $5.0 \mathrm{~Hz}, \mathrm{H}-16) .{ }^{13} \mathrm{C}-\mathrm{NMR}\left(125 \mathrm{MHz}, \mathrm{CDCl}_{3}\right): \delta \mathrm{c} 20.8\left(\mathrm{COCH}_{3}\right), 20.9\left(\mathrm{COCH}_{3}\right)$, 25.8 (C-2), 27.8 (C-3), 28.6 (C-5), 29.0 (C-4), 29.0 (C-6), 29.1 (C-8), 29.2 (C-7), 58.6 (C-11), 64.3 (C16), 64.6 (C-1), 68.6 (C-13), 70.8 (C-14), 74.9 (C-15), 80.1 (C-12), 119.7 (C-18), 127.7 (C-10), 132.0 (C-9), $134.6(\mathrm{C}-17), 169.4(\mathrm{C}=\mathrm{O}), 171.3(\mathrm{C}=\mathrm{O})$.

(11S, 16S,Z)-16-Hydroxyoctadeca-9,17-dien-12,14-diyne-1,11-diyl diacetate (OHR-10): yellowish oil $(110 \mathrm{mg}) ;[\alpha]_{\mathrm{D}}^{25}+285.2^{\circ}\left(c=1.01, \mathrm{CHCl}_{3}\right) ; \mathrm{UV}\left(\mathrm{CHCl}_{3}\right) \lambda \max (\log \xi): 208$ (1.40), 226 (3.15), 245 (4.81), and 268 (4.55) nm; IR (KBr) vmax: 3348, 3014, 2988, 2254, 1722, 1710, 1486, 1380, 1258, 1016 and 885 $\mathrm{cm}^{-1}$; ${ }^{1} \mathrm{H}-\mathrm{NMR}\left(500 \mathrm{MHz}, \mathrm{CDCl}_{3}\right): \delta_{\mathrm{H}} 1.26(8 \mathrm{H}, \mathrm{m}, \mathrm{H}-3, \mathrm{H}-4, \mathrm{H}-5, \mathrm{H}-6), 1.41(2 \mathrm{H}, \mathrm{m}, \mathrm{H}-7), 1.61(2 \mathrm{H}$, m, H-2), 2.04 (3H, s, COCH3), 2.07 (3H, s, COCH3), 2.13 (2H, q, 7.5 Hz, H-8), 4.05 (2H t, 7.5 Hz, H1), 4.94 (1H, brd, $5.0 \mathrm{~Hz}, \mathrm{H}-16), 5.25(1 \mathrm{H}, \mathrm{d}, 10.5 \mathrm{~Hz}, \mathrm{H}-18 \mathrm{a}), 5.50$ (1H, dt, 10.5, 7.5 Hz, Hz, H-9), 5.55 $(1 \mathrm{H}, \mathrm{dd}, 17.5,1.5 \mathrm{~Hz}, \mathrm{H}-18 \mathrm{~b}), 5.65$ (1H, ddt, 10.5, 7.5, 1.0Hz, H-10), 5.96 (1H, ddd, 17.0, 10.0, $1.5 \mathrm{~Hz}$, $\mathrm{H}-17), 6.13(1 \mathrm{H}, \mathrm{d}, 8.0 \mathrm{~Hz}, \mathrm{H}-11) .{ }^{13} \mathrm{C}-\mathrm{NMR}\left(125 \mathrm{MHz}, \mathrm{CDCl}_{3}\right): \delta \mathrm{c} 20.8\left(\mathrm{COCH}_{3}\right), 21.0\left(\mathrm{COCH}_{3}\right), 25.8$ (C-2), 27.8 (C-3), 28.6 (C-5), 29.0 (C-4), 29.0 (C-6), 29.1 (C-8), 30.4 (C-7), 58.6 (C-11), 64.3 (C-16), 64.6 (C-1), 68.6 (C-13), 70.8 (C-14), 74.9 (C-15), 80.1 (C-12), 117.3 (C-18), 123.9 (C-10), 130.8 (C-9), $136.2(\mathrm{C}-17), 169.5(\mathrm{C}=\mathrm{O}), 171.3(\mathrm{C}=\mathrm{O})$.

(11S, 16S,Z)-11-Hydroxyoctadeca-9-en-12,14-diyne-1,16-diyl diacetate (OHR-11): yellowish oil (30 $\mathrm{mg}) ;[\alpha]_{\mathrm{D}}^{25}+225.4^{\circ}\left(c=1.01, \mathrm{CHCl}_{3}\right) ; \mathrm{UV}\left(\mathrm{CHCl}_{3}\right) \lambda \max (\log \xi): 205$ (0.76), 223 (1.35), 240 (3.21), and 265 (4.05) nm; IR (KBr) vmax: 3310, 2985, 2258, 1723, 1716, 1585, 1477, 1238, 1028 and $954 \mathrm{~cm}^{-1}$; ${ }^{1} \mathrm{H}-$ NMR (500 MHz, CDCl 3 ): $\delta_{\mathrm{H}} 0.89(3 \mathrm{H}, \mathrm{t}, 7.5 \mathrm{~Hz}, \mathrm{H}-18), 1.28(8 \mathrm{H}, \mathrm{m}, \mathrm{H}-3, \mathrm{H}-4, \mathrm{H}-5, \mathrm{H}-6), 1.38$ (2H, m, H-7), 1.62 (2H, m, H-2), 1.78 (2H, m, H-17), $2.04\left(3 \mathrm{H}, \mathrm{s}, \mathrm{COCH}_{3}\right), 2.09$ (3, s, $\left.\mathrm{COCH}_{3}\right), 2.13(2 \mathrm{H}, \mathrm{q}$, $7.5 \mathrm{~Hz}, \mathrm{H}-8), 4.05(2 \mathrm{H}, \mathrm{t}, 7.0 \mathrm{~Hz}, \mathrm{H}-1), 5.33(1 \mathrm{H}, \mathrm{t}, 6.5 \mathrm{~Hz}, \mathrm{H}-16), 5.47$ (1H, ddt, 10.6, 7.5, $1.5 \mathrm{~Hz}, \mathrm{H}-$ 9), $5.66(1 \mathrm{H}, \mathrm{ddt}, 10.6,8.5,1.5 \mathrm{~Hz}, \mathrm{H}-10), 5.90(1 \mathrm{H}, \mathrm{d}, 8.5 \mathrm{~Hz}, \mathrm{H}-11) .{ }^{13} \mathrm{C}-\mathrm{NMR}\left(125 \mathrm{MHz}, \mathrm{CDCl}_{3}\right): \delta \mathrm{c}$ 9.2 (C-18), $20.8\left(\mathrm{COCH}_{3}\right), 20.9\left(\mathrm{COCH}_{3}\right), 25.8(\mathrm{C}-2), 27.8$ (C-8), 28.6 (C-6), 28.9 (C-5), $29.0(\mathrm{C}-4)$, 29.1 (C-3), 29.1 (C-7), 29.3 (C-17), 60.0 (C-11), 64.6 (C-16), 65.1 (C-1), 69.2 (C-13), 69.5 (C-14), 75.6 (C-15), $77.6(\mathrm{C}-12), 126.1(\mathrm{C}-10), 134.3(\mathrm{C}-9), 169.4(\mathrm{C}=\mathrm{O}), 171.2(\mathrm{C}=\mathrm{O})$.

(11S,16S,Z)-16-Hydroxyoctadeca-9-en-12,14-diyne-1,11-diyl diacetate (OHR-12): yellowish oil (80 mg); $[\alpha]_{\mathrm{D}}^{25}+241.4^{\circ}\left(c=1.21, \mathrm{CHCl}_{3}\right) ; \mathrm{UV}\left(\mathrm{CHCl}_{3}\right) \lambda \max (\log \xi): 204$ (0.86), 225 (1.25), 242 (3.61), and 266 (4.15) nm; IR (KBr) vmax: 3326, 2986, 2252, 1720, 1715, 1565, 1447, 1232, 1120 and $880 \mathrm{~cm}^{-1}$; ${ }^{1} \mathrm{H}-\mathrm{NMR}\left(500 \mathrm{MHz}, \mathrm{CDCl}_{3}\right): \delta \mathrm{H} 1.00(3 \mathrm{H}, \mathrm{t}, 7.5 \mathrm{~Hz}, \mathrm{H}-18), 1.29(8 \mathrm{H}, \mathrm{m}, \mathrm{H}-3, \mathrm{H}-4, \mathrm{H}-5, \mathrm{H}-6), 1.38(2 \mathrm{H}$, m, H-7), 1.62 (2H, m, H-2), 1.74 (2H, m, H-17), $2.04\left(3 \mathrm{H}, \mathrm{s}, \mathrm{COCH}_{3}\right), 2.07$ (3, s, $\left.\mathrm{COCH}_{3}\right), 2.15(2 \mathrm{H}, \mathrm{q}$, $7.5 \mathrm{~Hz}, \mathrm{H}-8), 4.06$ (2H, t, 7.0 Hz, H-1), 4.37 (1H, t, $6.5 \mathrm{~Hz}, \mathrm{H}-16), 5.48$ (1H, ddt, 10.6, 7.5, $1.5 \mathrm{~Hz}, \mathrm{H}-9)$, $5.66(1 \mathrm{H}, \mathrm{ddt}, 10.6,8.5,1.5 \mathrm{~Hz}, \mathrm{H}-10), 6.13(1 \mathrm{H}, \mathrm{d}, 8.5 \mathrm{~Hz}, \mathrm{H}-11) .{ }^{13} \mathrm{C}-\mathrm{NMR}\left(125 \mathrm{MHz}, \mathrm{CDCl}_{3}\right): \delta \mathrm{c} 9.2$ $(\mathrm{C}-18), 20.8\left(\mathrm{COCH}_{3}\right), 20.9\left(\mathrm{COCH}_{3}\right), 25.8(\mathrm{C}-2), 27.6(\mathrm{C}-8), 28.6(\mathrm{C}-6), 28.9(\mathrm{C}-5), 29.0(\mathrm{C}-4), 29.1$ (C-3), 29.3 (C-7), 30.6(C-17), 58.6 (C-11), 64.0 (C-16), 65.4 (C-1), 68.7 (C-13), 69.5 (C-14), 75.7 (C15), 81.1 (C-12), 124.0 (C-10), $136.1(\mathrm{C}-9), 169.4(\mathrm{C}=\mathrm{O}), 171.4(\mathrm{C}=\mathrm{O})$.

(3S,8S,Z)-18-Hydroxyoctadeca-9-en-4,6-diyne-3,8-diyl diacetate (OHR-13): yellowish oil (20 mg); $[\alpha]_{\mathrm{D}}^{25}+168.6^{\circ}\left(c=0.50, \mathrm{CHCl}_{3}\right) ; \mathrm{UV}\left(\mathrm{CHCl}_{3}\right) \lambda \max (\log \xi): 206(0.56), 226(1.55), 242(2.86)$, and 265 
(3.84) nm; IR (KBr) vmax: 3410, 3020, 2252, 1718, 1714, 1562, 1460, 1235, 1022 and $950 \mathrm{~cm}^{-1}$; ${ }^{1} \mathrm{H}-\mathrm{NMR}\left(500 \mathrm{MHz}, \mathrm{CDCl}_{3}\right): \delta_{\mathrm{H}} 1.00(3 \mathrm{H}, \mathrm{t}, 7.5 \mathrm{~Hz}, \mathrm{H}-1), 1.28$ (8H, m, H-13, H-14, H-15, H-16), 1.37 (2H, m, H-12), 1.61 (2H, m, H-17), 1.79 (2H, m, H-2), 2.04 (3H, s, COCH $), 2.09$ (3H, s, $\left.\mathrm{COCH}_{3}\right), 2.13$ (2H, q, 7.5 Hz, H-11), 4.08 (2H, t, 7.0 Hz, H-18), 5.33 (1H, t, $6.5 \mathrm{~Hz}, \mathrm{H}-3), 5.47$ (1H, ddt, 10.6, 7.5, 1.5 $\mathrm{Hz}, \mathrm{H}-10), 5.66$ (1H, ddt, 10.6, 8.5, $1.5 \mathrm{~Hz}, \mathrm{H}-9), 6.13$ (1H, d, $8.5 \mathrm{~Hz}, \mathrm{H}-8) .{ }^{13} \mathrm{C}-\mathrm{NMR}\left(125 \mathrm{MHz}, \mathrm{CDCl}_{3}\right)$ : $\delta$ c $9.2(\mathrm{C}-1), 20.8\left(\mathrm{COCH}_{3}\right), 21.0\left(\mathrm{COCH}_{3}\right), 25.8(\mathrm{C}-17), 27.8(\mathrm{C}-11), 28.6(\mathrm{C}-13), 28.9(\mathrm{C}-14), 29.0(\mathrm{C}-$ 15), 29.1 (C-16), 29.1 (C-12), 29.3 (C-2), 60.0 (C-8), 64.6 (C-3), 65.1 (C-18), 69.1 (C-6), 69.2 (C-5), 75.7 (C-4), 77.5 (C-7), 123.6 (C-9), $136.1(\mathrm{C}-10), 169.4(\mathrm{C}=\mathrm{O}), 169.7(\mathrm{C}=\mathrm{O})$.

(3S,8S,Z)-18-Hydroxyoctadeca-1,9-dien-4,6-diyne-3,8-diyl diacetate (OHR-14): yellowish oil (30 mg); $[\alpha]_{\mathrm{D}}^{25}+236.7^{\circ}\left(c=0.61, \mathrm{CHCl}_{3}\right) ; \mathrm{UV}\left(\mathrm{CHCl}_{3}\right) \lambda \max (\log \xi): 210(1.46), 228(2.15), 246$ (3.71), and 274 (4.65) nm; IR (KBr) vmax: 3380, 3010, 2252, 1718, 1713, 1568, 1438, 1310, 1016 and $890 \mathrm{~cm}^{-1}$; ${ }^{1} \mathrm{H}-\mathrm{NMR}\left(500 \mathrm{MHz}, \mathrm{CDCl}_{3}\right): \delta \mathrm{H} 1.31(8 \mathrm{H}, \mathrm{m}, \mathrm{H}-13, \mathrm{H}-14, \mathrm{H}-15, \mathrm{H}-16), 1.38(2 \mathrm{H}, \mathrm{m}, \mathrm{H}-12), 1.61(2 \mathrm{H}$, m, H-17), 2.04 (3H, s, COCH3), 2.07 (3H, s, COCH3), 2.14 (2H, q, 7.5 Hz, H-11), 4.09 (2H t, 7.5 Hz, H-17), 5.33 (1H, d, 10.5 Hz, H-1a), $5.46(1 \mathrm{H}, \mathrm{dt}, 10.5,7.5 \mathrm{~Hz}, \mathrm{~Hz}, \mathrm{H}-10), 5.53$ (1H, dd, 17.5, 1.5 Hz, H1b), $5.66(1 \mathrm{H}, \mathrm{ddt}, 10.5,7.5,1.0 \mathrm{~Hz}, \mathrm{H}-9), 5.85(1 \mathrm{H}, \mathrm{ddd}, 17.0,10.0,1.5 \mathrm{~Hz}, \mathrm{H}-2), 5.90(1 \mathrm{H}$, brd, $5.0 \mathrm{~Hz}, \mathrm{H}-3), 6.13(1 \mathrm{H}, \mathrm{d}, 8.0 \mathrm{~Hz}, \mathrm{H}-8) .{ }^{13} \mathrm{C}-\mathrm{NMR}\left(125 \mathrm{MHz}, \mathrm{CDCl}_{3}\right): \delta \mathrm{c} 20.8\left(\mathrm{COCH}_{3}\right), 20.9\left(\mathrm{COCH}_{3}\right)$, 25.8 (C-17), 27.8 (C-16), 28.6 (C-14), 29.0 (C-15), 29.0 (C-13), 29.1 (C-11), 29.2 (C-12), 60.0 (C-8), 64.3 (C-3), 64.6 (C-18), 69.1 (C-6), 70.7 (C-5), 75.1 (C-4), 76.7 (C-7), 119.7 (C-1), 123.7 (C-9), 131.9 $(\mathrm{C}-10), 136.3(\mathrm{C}-2), 169.3(\mathrm{C}=\mathrm{O}), 169.4(\mathrm{C}=\mathrm{O})$.

(3S,8S,Z)-3,18-Dihydroxyoctadeca-1,9-dien-4,6-diyn-8-yl acetate (OHR-15): yellowish oil (16 mg); $[\alpha]_{\mathrm{D}}^{25}+216.8^{\circ}\left(c=0.26, \mathrm{CHCl}_{3}\right) ; \mathrm{UV}\left(\mathrm{CHCl}_{3}\right) \lambda \max (\log \xi): 206(0.86), 228(2.35), 247$ (3.75), and 270 (4.25) nm; IR (KBr) Vmax: 3460, 3010, 2250, 1716, 1562, 1442, 1320, 1038 and $860 \mathrm{~cm}^{-1}$; ${ }^{1} \mathrm{H}-\mathrm{NMR}\left(500 \mathrm{MHz}, \mathrm{CDCl}_{3}\right): \delta_{\mathrm{H}} 1.31(8 \mathrm{H}, \mathrm{m}, \mathrm{H}-13, \mathrm{H}-14, \mathrm{H}-15, \mathrm{H}-16), 1.37(2 \mathrm{H}, \mathrm{m}, \mathrm{H}-12), 1.61(2 \mathrm{H}$, m, H-17), 2.07 (3H, s, COCH3), 2.14 (2H, q, 7.5 Hz, H-11), 4.09 (2H t, 7.5 Hz, H-17), 4.33 (1H, brd, $5.0 \mathrm{~Hz}, \mathrm{H}-3), 5.33(1 \mathrm{H}, \mathrm{d}, 10.5 \mathrm{~Hz}, \mathrm{H}-1 \mathrm{a}), 5.48$ (1H, dt, 10.5, $7.5 \mathrm{~Hz}, \mathrm{~Hz}, \mathrm{H}-10), 5.52$ (1H, dd, 17.5, 1.5 $\mathrm{Hz}, \mathrm{H}-1 \mathrm{~b}), 5.66(1 \mathrm{H}, \mathrm{ddt}, 10.5,7.5,1.0 \mathrm{~Hz}, \mathrm{H}-9), 5.92(1 \mathrm{H}, \mathrm{ddd}, 17.0,10.0,1.5 \mathrm{~Hz}, \mathrm{H}-2), 6.13(1 \mathrm{H}, \mathrm{d}$, $8.0 \mathrm{~Hz}, \mathrm{H}-8) .{ }^{13} \mathrm{C}-\mathrm{NMR}\left(125 \mathrm{MHz}, \mathrm{CDCl}_{3}\right): 20.9\left(\mathrm{COCH}_{3}\right), 25.8(\mathrm{C}-17), 27.8(\mathrm{C}-16), 28.6(\mathrm{C}-14), 29.0$ (C-15), 29.0 (C-13), 29.1 (C-11), 29.2 (C-12), 61.3 (C-8), 63.3 (C-3), 64.6 (C-18), 69.1 (C-6), 70.6 (C5), 75.6 (C-4), 79.8 (C-7), 119.7 (C-1), 127.8 (C-10), 132.1 (C-9), 136.4 (C-2), 169.4 (C=O).

(3S,8S,Z)-3,18-Dihydroxyoctadeca-1,9-dien-4,6-diyn-3-yl acetate (OHR-16): yellowish oil (20 mg); $[\alpha]_{\mathrm{D}}^{25}+176.4^{\circ}\left(c=0.16, \mathrm{CHCl}_{3}\right) ; \mathrm{UV}\left(\mathrm{CHCl}_{3}\right) \lambda \max (\log \xi): 203(0.75), 225$ (2.10), $248(2.65)$, and 266 (4.86) nm; IR (KBr) $v_{\max }: 3410,3022,2258,1720,1582,1432,1360,1024$ and $860 \mathrm{~cm}^{-1}$; ${ }^{1} \mathrm{H}-\mathrm{NMR}(500$ $\left.\mathrm{MHz}, \mathrm{CDCl}_{3}\right): \delta_{\mathrm{H}} 1.31$ (8H, m, H-13, H-14, H-15, H-16), 1.37 (2H, m, H-12), 1.61 (2H, m, H-17), 2.04 (3H, s, COCH3), 2.14 (2H, q, 7.5 Hz, H-11), 4.09 (2H t, $7.5 \mathrm{~Hz}, \mathrm{H}-17), 5.13$ (1H, d, 8.0 Hz, H-8) 5.33 $(1 \mathrm{H}, \mathrm{d}, 10.5 \mathrm{~Hz}, \mathrm{H}-1 \mathrm{a}), 5.48(1 \mathrm{H}, \mathrm{dt}, 10.5,7.5 \mathrm{~Hz}, \mathrm{~Hz}, \mathrm{H}-10), 5.52(1 \mathrm{H}, \mathrm{dd}, 17.5,1.5 \mathrm{~Hz}, \mathrm{H}-1 \mathrm{~b}), 5.68$ $(1 \mathrm{H}$, ddt, 10.5, 7.5, 1.0Hz, H-9), $5.90(1 \mathrm{H}$, brd, $5.0 \mathrm{~Hz}, \mathrm{H}-3), 5.92(1 \mathrm{H}, \mathrm{ddd}, 17.0,10.0,1.5 \mathrm{~Hz}, \mathrm{H}-2)$. ${ }^{13} \mathrm{C}-\mathrm{NMR}\left(125 \mathrm{MHz}, \mathrm{CDCl}_{3}\right): 20.9\left(\mathrm{COCH}_{3}\right), 25.8(\mathrm{C}-17), 27.8(\mathrm{C}-16), 28.6(\mathrm{C}-14), 29.0(\mathrm{C}-15), 29.0$ (C-13), 29.1 (C-11), 29.2 (C-12), 61.3 (C-8), 63.3 (C-3), 64.6 (C-18), 69.1 (C-6), 70.6 (C-5), 75.5 (C-4), 77.8 (C-7), 117.2 (C-1), 129.2 (C-10), 134.4 (C-9), 136.4 (C-2), 169.3 (C=O). 


\subsection{Anticancer Assay}

\subsubsection{Cancer Cell Lines and Culture}

The human breast cancer cell lines MCF-7, MDA-MB-231, human hepatocellular liver cell line HepG2 and human lung carcinoma epithelial cells A549 were purchased from American Type Culture Collection (ATCC, Manassas, VA, USA). Normal human hepatic LO2 cells were obtained from the Institute of Cell Biology, Academic Sinica (Shanghai, China). The cells were grown in an atmosphere of $5 \% \mathrm{CO}_{2}$ at $37{ }^{\circ} \mathrm{C}$ in RPMI 1640 medium supplemented with $10 \%$ fetal bovine serum, $100 \mathrm{U} / \mathrm{mL}$ penicillin and $100 \mathrm{mg} / \mathrm{mL}$ streptomycin.

\subsubsection{Measurement of Cell Viability}

The viability of cells was measured by a colorimetric MTT assay. Briefly, $1 \times 10^{4}$ cells/well in 96well microplates were exposed to different concentration of polyynes and their acetylated derivatives respectively for $24 \mathrm{~h}$ incubation, following addition of $20 \mu \mathrm{L}$ MTT solution $(4 \mathrm{mg} / \mathrm{mL}$ ) to each well for another $4 \mathrm{~h}$ incubation at $37^{\circ} \mathrm{C}$. Finally, the medium was removed and replaced with $100 \mu \mathrm{L}$ dimethyl sulfoxide which was added to dissolve the dye crystal presented in cells. The absorbance was recorded at $570 \mathrm{~nm}$ using a microplate reader (1420 Multilabel counter victor ${ }^{3}$, Perkin-Elmer, Waltham, MA, USA). The results were expressed as ratio of absorbance between treatments and control cells (solvent vehicle set at $100 \%$ ). Four replicate wells were tested per assay which was repeated three times.

\subsubsection{Hoechst Staining}

MDA-MB-231 cells were seeded in the flat-bottomed 6-well plates and treated with $\mathbf{O H R - 1 , - 2 , - 3}$ and -5. Cells treated with solvent vehicle served as controls. In $12 \mathrm{~h}$ after treatment, cells were fixed in $4 \%$ polyoxymethylene solution for $30 \mathrm{~min}$ and then washed with PBS. The fixed cells were incubated with Hoechst 33342 for 15 min at room temperature in the dark and then washed with PBS twice, which were finally observed under a fluorescence microscope (Convert Fluorescence Microsope Axiovert 200, HAL 100, HBO 100, Carl Zeiss MicroImaging Co., Ltd., Oberkochen, Germany) at a magnification of $\times 400$.

\subsubsection{Measurement of Mitochondrial Membrane Potential}

To assess the mitochondrial membrane potential, $\Delta \psi \mathrm{m}, \mathrm{JC}-1$ staining was used to exhibit potential dependent accumulation in mitochondria, indicating reversibly change color from green to red fluorescence as the membrane potential increases. On the other hand, in apoptotic or unhealthy cells with low $\Delta \psi \mathrm{m}$, JC-1 showed an increasing ratio of green to red fluorescence intensity. The MDA-MB231 cells were treated with OHR-1, -2, $\mathbf{- 3}$ and $\mathbf{- 5}$ for $24 \mathrm{~h}$ in a humidified atmosphere $\left(37^{\circ} \mathrm{C}\right.$ with $5 \%$ $\left.\mathrm{CO}_{2}\right)$. The cells were collected and responded in $0.5 \mathrm{~mL}$ culture medium with JC-1 dye $(1 \mu \mathrm{g} / \mathrm{mL})$ for 20 min at $37^{\circ} \mathrm{C}$ in dark. Fluorescence was monitored by both flow cytometry (BD Biosciences, San Jose, $\mathrm{CA}, \mathrm{USA}$ ) and fluorescence microscope. The $\Delta \psi \mathrm{m}$ were indicated by the rato of green to red fluorescence intensity. The data were expressed as ratio of $\Delta \psi \mathrm{m}$ between treatments and control cells (solvent vehicle set at $100 \%$ ). 


\subsubsection{Cell Cycle Analysis by Flow Cytometry}

Cells were seeded in 6-well tissue culture plates and treated with DMSO control or different concentration of OHR-1, -2, -3 and -5 for $24 \mathrm{~h}$. Then, the cells were harvested and fixed gently with cold $70 \%$ ethanol at $-20^{\circ} \mathrm{C}$ overnight. Finally, the cells were washed with PBS and re-suspended in 300 $\mu \mathrm{L}$ of propidium iodide (PI) stain solution $(20 \mu \mathrm{g} / \mathrm{mL}$ PI and $8 \mu \mathrm{g} / \mathrm{mL}$ DNase-free RNase) for $20 \mathrm{~min}$ at room temperature in the dark. The cells were analyzed with a flow cytometry and Mod Fit LT 3.0 software (Variety Software House, Topsham, ME, USA). For each measurement, at least 20,000 cells were counted.

\subsubsection{Statistical Analysis}

Data were presented as mean \pm SEM of at least three independent experiments performed in quadruplicates for each sample. A one-way analysis of variance (ANOVA) followed by Turkey post-hoc test (GraphPad Prism 6.0, San Diego, CA, USA) determined whether the results had statistical significance between groups. Values of $p<0.05$ were considered as statistical significance.

\section{Conclusions}

Six polyynes, namely falcarindiol (OH-1), oplopandiol (OH-2), (11S,16S,9Z)-9,17-octadecadiene12,14-diyne-1,11,16-triol,1-acetate (OH-3), oplopandiol acetate (OH-4), oplopantriol A (OH-5) and oplopantriol B (OH-6), had been isolated and identified from the root bark of Oplopanax horridus (Devil's Club) - a natural dietary supplement and medicinal plant in North America. Sixteen acetylated polyynes were synthesized from the isolated polyynes. The polyynes presented different inhibitory effects on four human cancer cell lines. Primary structure-activity analysis showed that the observed inhibitions were influenced mostly by the terminal ethenyl and hydroxyl groups and acylations of the polyynes. This study showed that acetylated polyynes retained the same anti-proliferative activity mechanism as non-acetylated polyynes. Moreover, the safety evaluation on the usage of $O$. horridus is worthy of study in future.

\section{Acknowledgments}

This work was supported in part by the NIH/NCCAM (AT004418 and AT005362 to C.-S.Y.) and University of Macau (MYRG085).

\section{Author Contributions}

C.Z.W., C.S.Y. and S.P.L. designed this study. L.Z.M. and W.H.H. performed the experiments. L.Z.M. and W.H.H. draft the manuscript. All authors have read and approved the final manuscript.

\section{Conflicts of Interest}

The author declares no conflict of interest. 


\section{References}

1. Christensen, L.P. Aliphatic C(17)-polyacetylenes of the falcarinol type as potential health promoting compounds in food plants of the Apiaceae family. Recent Pat. Food Nutr. Agric. 2011, 3, 64-77.

2. Pan, Y.; Lowary, T.L.; Tykwinski, R.R. Naturally occurring and synthetic polyyne glycosides. Can. J. Chem. 2009, 87, 1565-1582.

3. Siddiq, A.; Dembitsky, V. Acetylenic anticancer agents. Anti-Cancer Agent. Med. Chem. 2008, 8, 132-170.

4. Minto, R.E.; Blacklock, B.J. Biosynthesis and function of polyacetylenes and allied natural products. Prog. Lipid Res. 2008, 47, 233-306.

5. Shi Shun, A.L.K.; Tykwinski, R.R. Synthesis of naturally occurring polyynes. Angew. Chem. Int. Ed. 2006, 45, 1034-1057.

6. Christensen, L.P.; Brandt, K. Bioactive polyacetylenes in food plants of the Apiaceae family: Occurrence, bioactivity and analysis. J. Pharm. Biomed. Anal. 2006, 41, 683-693.

7. Metzger, B.T.; Barnes, D.M. Polyacetylene diversity and bioactivity in orange market and locally grown colored carrots (Daucus carota L.). J. Agric. Food Chem. 2009, 57, 11134-11139.

8. Metzger, B.T.; Barnes, D.M.; Reed, J.D. Purple carrot (Daucus carota L.) polyacetylenes decrease lipopolysaccharide-induced expression of inflammatory proteins in macrophage and endothelial cells. J. Agric. Food Chem. 2008, 56, 3554-3560.

9. Li, C.; Lee, D.; Graf, T.N.; Phifer, S.S.; Nakanishi, Y.; Riswan, S.; Setyowati, F.M.; Saribi, A.M.; Soejarto, D.D.; Farnsworth, N.R.; et al. Bioactive constituents of the stem bark of mitrephora glabra. J. Nat. Prod. 2009, 72, 1949-1953.

10. Lantz, T.C.; Antos, J.A. Clonal expansion in the deciduous understory shrub, Devil's club (Oplopanax horridus; Araliaceae). Can. J. Bot. 2002, 80, 1052-1062.

11. Nukhimovskii, E.L.; Zhurba, O.V. Ecological morphology of certain medicinal plants growing under natural conditions 8. Oplopanax elatus. Rastitel'nye Resursy 1979, 15, 507-516.

12. Smith, G.W. Arctic pharmacognosia .2. devils club, Oplopanax horridus. J. Ethnopharm. 1983, 7 , 313-320.

13. Gottesfeld, L.M.J. The importance of bark products in the aboriginal economies of northwestern british-columbia, Canada. Econ. Bot. 1992, 46, 148-157.

14. Gottesfeld, L.M.J. Wet'Suwet'en ethnobotany: Traditional plant uses. J. Ethnobiol. 1994, 14, 185-210.

15. McCutcheon, A.R.; Roberts, T.E.; Gibbons, E.; Ellis, S.M.; Babiuk, L.A.; Hancock, R.E.W.; Towers, G.H.N. Antiviral screening of British Columbian medicinal plants. J. Ethnopharm. 1995, $49,101-110$.

16. Sun, S.; Li, X.L.; Wang, C.Z.; Williams, S.; Yuan, C.S. Improving anticancer activities of Oplopanax horridus root bark extract by removing water-soluble components. Phytother. Res. 2010, 24, 1166-1174.

17. Sun, S.; Du, G.J.; Qi, L.W.; Williams, S.; Wang, C.Z.; Yuan, C.S. Hydrophobic constituents and their potential anticancer activities from Devil's Club (Oplopanax horridus Miq.). J. Ethnopharm. 2010, 132, 280-285. 
18. Li, X.L.; Sun, S.; Du, G.J.; Qi, L.W.; Williams, S.; Wang, C.Z.; Yuan, C.S. Effects of Oplopanax horridus on human colorectal cancer cells. Anticancer Res. 2010, 30, 295-302.

19. Huang, W.H.; Zhang, Q.W.; Wang, C.Z.; Yuan, C.S.; Li, S.P. Isolation and identification of two new polyynes from a north american ethnic medicinal plant-Oplopanax horridus (Smith) miq. Molecules 2010, 15, 1089-1096.

20. Purup, S.; Larsen, E.; Christensen, L.P. Differential effects of falcarinol and related aliphatic C(17)polyacetylenes on intestinal cell proliferation. J. Agric. Food Chem. 2009, 57, 8290-8296.

21. Wang, C.Z.; Zhang, Z.; Huang, W.H.; Du, G.J.; Wen, X.D.; Calway, T.; Yu, C.; Nass, R.; Zhao, J.; $\mathrm{Du}, \mathrm{W}$; et al. Identification of potential anticancer compounds from Oplopanax horridus. Phytomedicine 2013, 20, 999-1006.

22. Tai, J.; Cheung, S.S.; Ou, D.; Warnock, G.L.; Hasman, D. Antiproliferation activity of Devil's club (Oplopanax horridus) and anticancer agents on human pancreatic cancer multicellular spheroids. Phytomedicine 2014, 21, 506-514.

23. Huang, W.H.; Zhang, Q.W.; Yuan, C.S.; Wang, C.Z.; Li, S.P.; Zhou, H.H. Chemical constituents of the plants from the genus Oplopanax. Chem. Biodiver. 2014, 11, 181-196.

24. McGill, C.M.; Alba-Rodriguez, E.J.; Li, S.; Benson, C.J.; Ondrasik, R.M.; Fisher, L.N.; Claxton, D.F.; Barth, B.M. Extracts of Devil's club (Oplopanax horridus) exert therapeutic efficacy in experimental models of acute myeloid leukemia. Phytother. Res. 2014, 28, doi:10.1002/ptr.5129.

Sample Availability: Samples of the compounds are available from the authors.

(C) 2014 by the authors; licensee MDPI, Basel, Switzerland. This article is an open access article distributed under the terms and conditions of the Creative Commons Attribution license (http://creativecommons.org/licenses/by/3.0/). 